A. Carrero-Parreño et al.

\title{
Optimization of multistage membrane distillation system for treating shale gas produced water
}

Alba Carrero-Parreño ${ }^{a}$, Viviani C. Onishi ${ }^{a}$, Rubén Ruiz-Femenia ${ }^{a, b}$, Raquel SalcedoDíaz $^{a, b^{*}}$, José A. Caballero ${ }^{a, b}$, Juan A. Reyes-Labarta ${ }^{a, b}$

${ }^{a}$ Institute of Chemical Process Engineering, University of Alicante, Ap Correos 99, Alicante 03080, Spain

${ }^{b}$ Department of Chemical Engineering, University of Alicante, Ap Correos 99, Alicante 03080, Spain

* Corresponding author at. Institute of Chemical Process Engineering, University of Alicante, Ap Correos 99, Alicante 03080, Spain. Phone: +34 965903400. E-mail: raquel.salcedo@ua.es 
A. Carrero-Parreño et al.

\section{ABSTRACT}

Thermal membrane distillation (MD) is an emerging technology to desalinate highsalinity wastewaters, including shale gas produced water to reduce the corresponding water footprint of fracturing operations. In this work, we introduce a rigorous optimization model with energy recovery for the synthesis of multistage direct contact membrane distillation (DCMD) system. The mathematical model (implemented in GAMS software) is formulated via generalized disjunctive programming (GDP) and mixed-integer nonlinear programming (MINLP). To maximize the total amount of water recovered, the outflow brine is fixed close to salt saturation conditions (300 $\mathrm{g} \cdot \mathrm{kg}^{-}$ ${ }^{1}$ water) approaching zero liquid discharge (ZLD).

A sensitivity analysis is performed to evaluate the system's behavior under different uncertainty sources such as the heat source availability and inlet salinity conditions. The results emphasize the applicability of this promising technology, especially with low steam cost or waste heat, and reveal variable costs and system configurations depending on inlet conditions. For a produced water salinity ranging from $150 \mathrm{~g} \cdot \mathrm{kg}^{-1}$ water to 250 $\mathrm{g} \cdot \mathrm{kg}^{-1}$ water based on Marcellus play, an optimal treating cost are between 11.5 and 4.4 US $\$ \mathrm{~m}^{-3}$ is obtained when using low-cost steam. This cost can decrease to 2.8 US\$ $\mathrm{m}^{-3}$ when waste heat from shale gas operations is used.

Keywords: shale gas water, zero liquid discharge (ZLD), membrane distillation, optimal configuration 
A. Carrero-Parreño et al.

\section{Introduction}

Unconventional shale gas is an energy resource with the potential to change the global energy market, particularly considering the continuous increase in the demand for energy on a worldwide scale (Department of Energy \& Climate Change, 2013; Hammond and O’Grady, 2017; U.S. Energy Information Administration, 2017).

Shale gas trapped in shale formations is released by injecting large amounts of water $\left(10,500-38,000 \mathrm{~m}^{3}\right.$ per well) under high pressure to fracture the impermeable rock (hydraulic fracturing) (Jacquet, 2014; Yang et al., 2014). Part of the injected fluid (1040\%) called flowback water is recovered containing total dissolved solids (TDS) ranging from 10,000 to $150,000 \mathrm{mg} \cdot \mathrm{L}^{-1}$, taking from between a few days to a few weeks. The wastewater that is generated over the rest of the life of the well (10 - 30 years) is called produced water. The TDS concentration in long-term produced water can reach 250,000 mg. $\mathrm{L}^{-1}$ (U.S. Environmental Protection Agency, 2016).

Current water management strategies include disposal of wastewater via Class II disposal wells, transfer to a centralized water treatment facility (CWT) or, direct reuse in drilling subsequent wells. Direct reuse (without any treatment) in drilling subsequent wells is currently the most popular option due to its operational simplicity for contractors (Ruyle and Fragachan, 2015). However, as the number of drilled wells decrease, this practice becomes less attractive. Specifically, as can be seen in Fig. 1, the volume of fracturing fluid required to fracture new wells may be less than the volume of water generated by producing wells in the area. Consequently, operators must find a viable, sustainable and bearable wastewater management alternative when wastewater generation exceeds the water demand for fracturing. 
A. Carrero-Parreño et al.

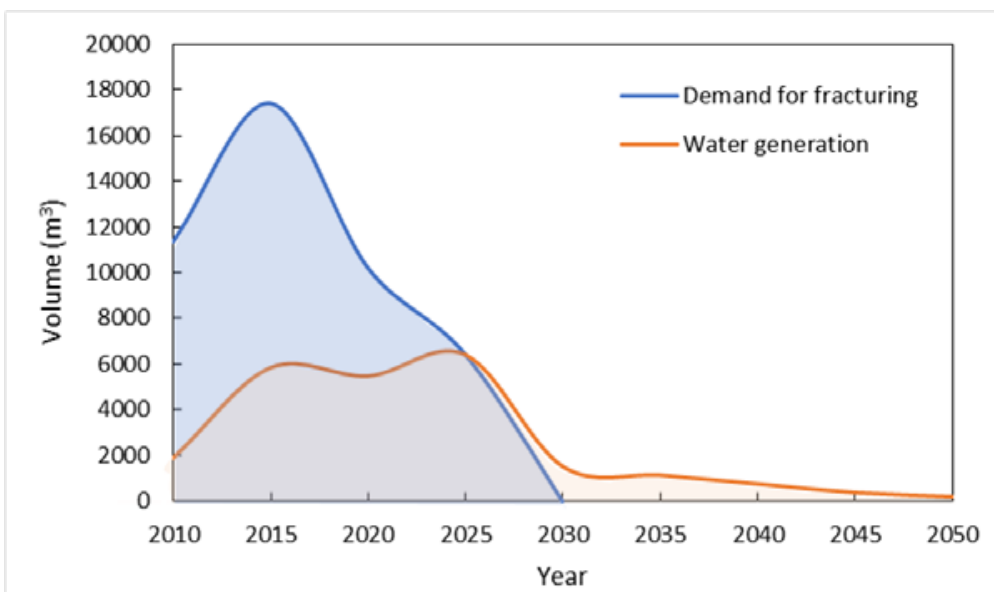

Fig. 1. Forecast of flowback and produced water generation and water demand over time (U.S. Environmental Protection Agency, 2016).

Shaffer et al. (2013) critically review mechanical vapor compression (MVC), membrane distillation (MD) and forward osmosis (FO) as suitable technologies to desalinate wastewater from shale gas operations. Onishi et al. (2017a, 2017b) developed a nonlinear programming (NLP) model for the optimal design of single and multi-effect evaporation (SEE/MEE) systems with/without mechanical vapor recompression (MVR). Regarding FO optimization for treating shale gas water, Salcedo-Díaz et al. (2017) proposed a hybrid treatment combining FO with reverse osmosis (RO). Their solution shows a trade-off between fracturing water cost and freshwater consumption. MD offers a great potential to treat shale gas water since the separation occurs below the normal boiling point of the inlet stream, therefore, it is possible to use waste heat to induce the separation (Ashoor et al., 2016; Drioli et al., 2015). This technology is especially advantageous in remote unconventional hydrocarbon extraction sites where electrical energy supply is not available and many waste heating sources are present, such as geothermal heat energy process facilities, or flaring (Chafidz et al., 2016; Deshmukh et al., 2018; Elsayed et al., 2015; Kim et al., 2017; Omkar R. Lokare et al., 2017). Furthermore, MD is also very attractive for this application due to its mobility, 
A. Carrero-Parreño et al.

modularity, and compactness, contrasting with conventional thermal desalination processes which involve a huge physical footprint (Silva et al., 2017).

Regarding membrane distillation optimization for the treatment of shale gas wastewater, Elsayed et al. (2015) have developed an optimization approach for treating flowback water by using direct contact membrane distillation (DCMD). However, they consider that waste energy is always available, hence there is no calculation of the energy cost or heat integration within the process streams. Moreover, in their optimization model, they do not consider process configuration design. Lokare et al., (2017) also evaluate the synergies and potential of DCMD technology for the treatment of shale gas water utilizing waste heat available from natural gas extraction. They simulate DCMD in ASPEN Plus and calibrate the model using laboratory-scale experiment. Then, the model is used to design and determine the operating parameters for a full-scale DCMD system. In a later work (Tavakkoli et al., 2017), the same authors highlighted the applicability of DCMD for treating shale gas water by evaluating the economic feasibility. Recently, Deshmukh et al. (2018) highlighted the advantages of MD for small-scale desalination applications and emphasized the benefits for desalinating shale gas water. However, they remark that the viability of MD as an energy-efficient treatment remains uncertain. Moreover, they mention the necessity of comparison techniques to obtain more reliable cost and process optimization.

To the best of our knowledge, there are no published optimization models for determining the optimal working conditions and membrane modules configuration for the MD treatment of shale gas produced water. For this reason, we introduce a mathematical model to optimize multistage membrane distillation systems (MDS) (including all potential membrane configurations in series and interconnections) for high-salinity conditions. The target of the MDS is to reduce the shale gas wastewater 
A. Carrero-Parreño et al.

volume as much as possible by producing concentrated saline water close to Zero Liquid Discharge (ZLD) - outlet flowrate water at near saturated conditions maximizing at the same time the total water recovered at the minimum cost. The model is mathematically formulated as a Generalized Disjunctive Programming (GDP) problem (Trespalacios and Grossmann, 2014) and reformulated as a Mixed Integer NonLinear Programming (MINLP) model to be solved using GAMS software (Rosenthal, 2016), seeking to minimize the total annualized cost of the process.

The main novelties of this study are: (1) development of an optimization model for MDS to attain close to ZLD conditions for the treatment of shale gas produced water; (2) optimization and design of full-scale membrane distillation systems coupled with heat recovery to determine the optimal system configuration and optimal working conditions; (3) application of the proposed model to real inlet flowrate and variable high-salinity to evaluate if the projected technology can be applied to desalinate produced water coming from different shale gas basins; and, (4) analysis of the economic viability of MD in shale gas operations.

The rest of the paper is organized as follows: section 2 describes the problem statement and the mathematical MINLP model; section 3 presents the case studies and section 4 the main results obtained. In addition, a critical appraisal for the sensitivity analysis is included; and section 5 summarizes the conclusions of the work.

\section{Problem statement and mathematical model}

The given parameters are: the defined wastewater feed stream (inlet mass flowrate, salinity, and temperature); the corresponding membrane characteristics (permeability and thickness); and, the cost of the membrane, pumps, heat exchangers and the utilities used (low-pressure steam and cooling water). The objective function considers the equipment's annualized capital cost of expenditure and the operating costs related to 
A. Carrero-Parreño et al.

membrane labor, replacement, and energy demand. Additionally, improving process cost-effectiveness by achieving conditions close to ZLD reduces water footprint by reducing brine discharges and increasing water recovery.

The multistage superstructure proposed for treating produced water is shown in Fig. 2. The superstructure comprises $n$ possible membrane modules in series and allows the possibility of various recycle connections. For instance, part of the concentrate obtained in stage two could be recycled in the same stage or could be sent to the first stage. There is only the possibility of recirculating the concentrated water to previous stages. On the other hand, if a membrane stage of the superstructure is not selected, the concentrated stream circulates through a bypass to the next stage.

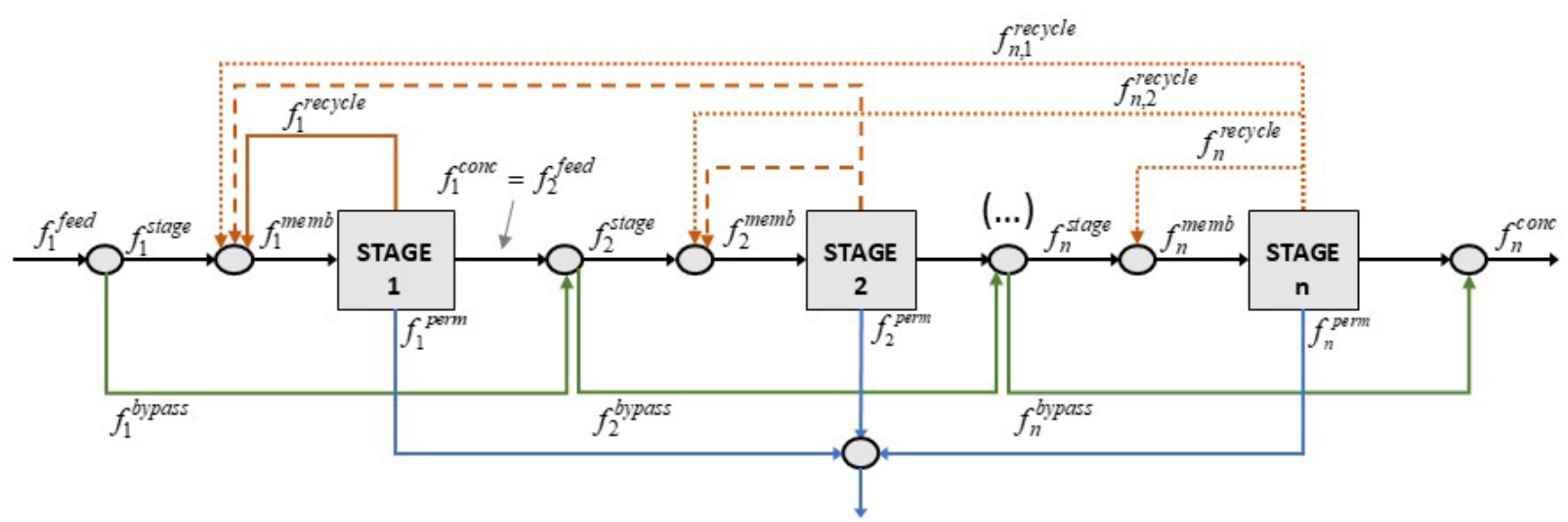

Fig. 2. Multistage Membrane Distillation superstructure for treating produced water from shale gas production.

DCMD is the configuration selected since it is recognized as the most suitable for purification of feed streams with non-volatile solutes and for small-scale desalination (Duong et al., 2015). Fig. 3 shows the scheme of a DCMD module including heat recovery (Swaminathan et al., 2016). Each membrane module is composed of the following equipment: shell and tube heat exchanger, heater and cooler; polytetrafluoroethylene membranes with polypropylene support; centrifugal pumps and 
storage tanks. The feed flowrate is heated before entering the membrane cell to induce the separation of salts and water. The driving force in DCMD is temperature difference between the inlet warm feed stream and ambient temperature of the permeate stream, which causes a difference of vapor pressures. To reduce the operational energy cost, a heat exchanger is used to preheat the inlet water with the hot permeate stream. Additionally, an external cooler is installed to cold down the recirculated permeate stream to generate a temperature difference across the membrane. To attain the specified outlet conditions, the concentrated stream leaving the membrane can also be recycled. Indeed, concentrate recycling is required for high recovery ratios (Lokare et al., 2018). The recirculated water of both sides of the membranes is stored in tanks installed in the feed and permeate loop, respectively. Finally, pumps are placed at the beginning of each stage and on the feed and permeate loop of each module to drive the recirculated water.

Throughout the work, we refer to heat exchangers when there is heat exchange between two streams within the system. Note that preheaters and coolers are also considered as heat exchangers but using external utilities.

Apart from the selection of the number of stages, the following decision variables are also calculated for each stage: membrane area; area and heating/cooling utility needed in the preheater and cooler; heat exchanger area; outlet concentration; recycle ratio; and operating temperatures. 
A. Carrero-Parreño et al.

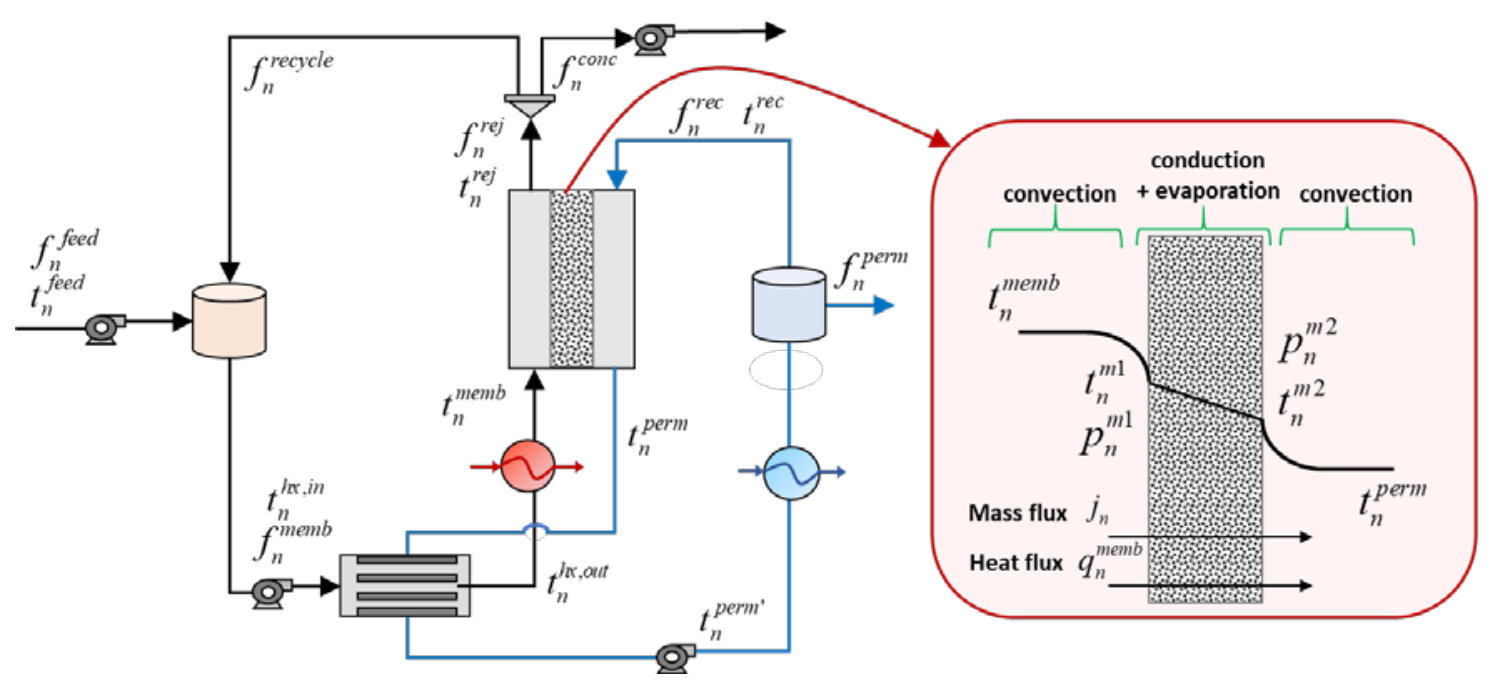

Fig. 3. Direct Contact Membrane Distillation module with heat recovery.

To simplify the mathematical formulation of the model, we have considered the following assumptions: steady state operation; heat losses in pipes, pumps, heater, and cooler are neglected; pressure drops in all thermal and mechanical equipment are negligible; vaporization takes place on the surface of the membrane; water with zero salinity goes through the membrane pores (permeate); and capital costs of mixers, splitters, pumps, tanks, and pipes are negligible.

The mathematical model, which includes equality and inequality constraints, logic propositions, data restriction and an objective function for the optimal multistage MDS, is formulated via Generalized Disjunctive Programming (GDP) and solved as a mixedinteger non-linear programming (MINLP) problem of the form:

$$
\begin{aligned}
& \min \text { Cost } \\
& \text { s.t. } \quad h(z)=0 \\
& \quad g(z) \leq 0 \\
& z \in \mathrm{R}^{n}
\end{aligned}
$$

where $\mathrm{z}$ is a vector of continuous variables representing temperatures, flowrates and concentrations of the streams. In this case, the objective function represents the cost of the process. The equality set of constraints, $h(z)=0$, are mass and energy balances and 
the MD performance equations; and the set of inequalities, $g(z) \leq 0$, are the design specifications.

The optimization problem is modeled using total flows and salt composition as variables, which involves bilinear terms - the multiplication of two variables - in the salt water mass balances. These terms are one of the sources of the non-convexity; however, this representation is advantageous because the bounds of the variables can be easily determined. Note that throughout the mathematical model description, lower case letters are used for variables and capital letters for parameters.

The following data are assumed to be known:

$\begin{array}{ll}F^{\text {feed }} & \text { Inlet mass flowrate, } \mathrm{kg} \cdot \mathrm{s}^{-1} \\ T^{\text {feed }} & \text { Inlet temperature, }{ }^{\circ} \mathrm{C} \\ X^{\text {feed }} & \text { Inlet salinity, } \mathrm{g} \cdot \mathrm{kg}^{-1} \\ X^{\text {zld }} & \text { Outlet salinity, } \mathrm{g} \cdot \mathrm{kg}^{-1} \\ E & \text { Membrane thickness, } \mathrm{mm} \\ B & \text { Membrane permeability, } \mathrm{kg}\left(\mathrm{m}^{2} \cdot \mathrm{Pa} \cdot \mathrm{h}\right)^{-1} \\ U^{\text {preh }} & \text { Overall heat transfer coefficient of the preheater, } \mathrm{kW}\left(\mathrm{m}^{2}{ }^{\circ} \mathrm{C}\right)^{-1} \\ U^{\text {cooler }} & \text { Overall heat transfer coefficient of the cooler, } \mathrm{kW}\left(\mathrm{m}^{2}{ }^{\circ} \mathrm{C}\right)^{-1} \\ T^{\text {steam }} & \text { Steam low-pressure temperature, }{ }^{\circ} \mathrm{C} \\ T^{\text {refrig,in }} & \text { Cooling water inlet temperature, }{ }^{\circ} \mathrm{C} \\ T^{\text {refrig,out }} & \text { Cooling water outlet temperature, }{ }^{\circ} \mathrm{C} \\ \Delta T^{\text {min }} & \text { Minimum temperature difference }\end{array}$

\subsection{Membrane distillation model}

To develop the MINLP model, he following set is defined.

$$
N=\{n / n \text { is a stage of membrane in series }\} \text {. }
$$


A. Carrero-Parreño et al.

The simplest equations such as mass and salt balance around each membrane distillation unit, recycle splitter and mixer are detailed in Appendix A, Section A.1 to the interested reader.

The energy balance across the membrane can be evaluated as follows,

$$
\begin{array}{ll}
h_{n}^{s}\left(t_{n}^{\text {memb }}, x_{n}^{\text {memb }}\right) \cdot f_{n}^{\text {memb }}-h_{n}^{s}\left(t_{n}^{r e j}, x_{n}^{r e j}\right) \cdot f_{n}^{r e j}=a_{n}^{\text {memb }} \cdot q_{n}^{\text {memb }} & \forall n \in N \\
h_{n}^{p}\left(t_{n}^{\text {perm }}\right) \cdot\left(f_{n}^{r e c}+f_{n}^{\text {perm }}\right)-h_{n}^{p}\left(t_{n}^{r e c}\right) \cdot f_{n}^{r e c}=a_{n}^{\text {memb }} \cdot q_{n}^{\text {memb }} \quad \forall n \in N
\end{array}
$$

where, $a_{n}^{\text {memb }}$ and $q_{n}^{\text {memb }}$ represent the membrane area and the heat transfer flux through the membrane. $h_{n}^{S}$ and $h_{n}^{p}$ are the specific enthalpies of saline water and permeate calculated at the specified conditions, correspondingly. Their values are calculated by the following rigorous correlations,

$$
h_{n}^{S}=-15970+4.105 \cdot t_{n}+8924 \cdot x_{n}-3.709 \cdot t_{n} \cdot x_{n}+84.77 \cdot x_{n}^{2} \quad \forall n \in N
$$

$$
h_{n}^{p}=-15970+4.1178 \cdot t_{n} \quad \forall n \in N
$$

where $t_{n}$ and $x_{n}$ are the corresponding temperature and composition.

These correlations have been generated using the maxmin approach - maximize the minimum distance between two sample points - considering temperature ranging from 0 ${ }^{\circ} \mathrm{C}$ to $100{ }^{\circ} \mathrm{C}$, and brine salinity between 0 to $400 \mathrm{~g} \cdot \mathrm{kg}^{-1}$ water. Aspen HYSYS ${ }^{\circledR}$ simulator has been used to obtain the specific enthalpies by using the thermodynamic package NRTL electrolytes.

It is important to highlight that these rigorous correlations are crucial to simulate the real behavior of the MDS since the specific enthalpies in saline streams are significantly 
dependent on temperature and composition. Fig. 4 shows the surface plot of enthalpy as a function of salinity and temperature and the relative error obtained for each point.
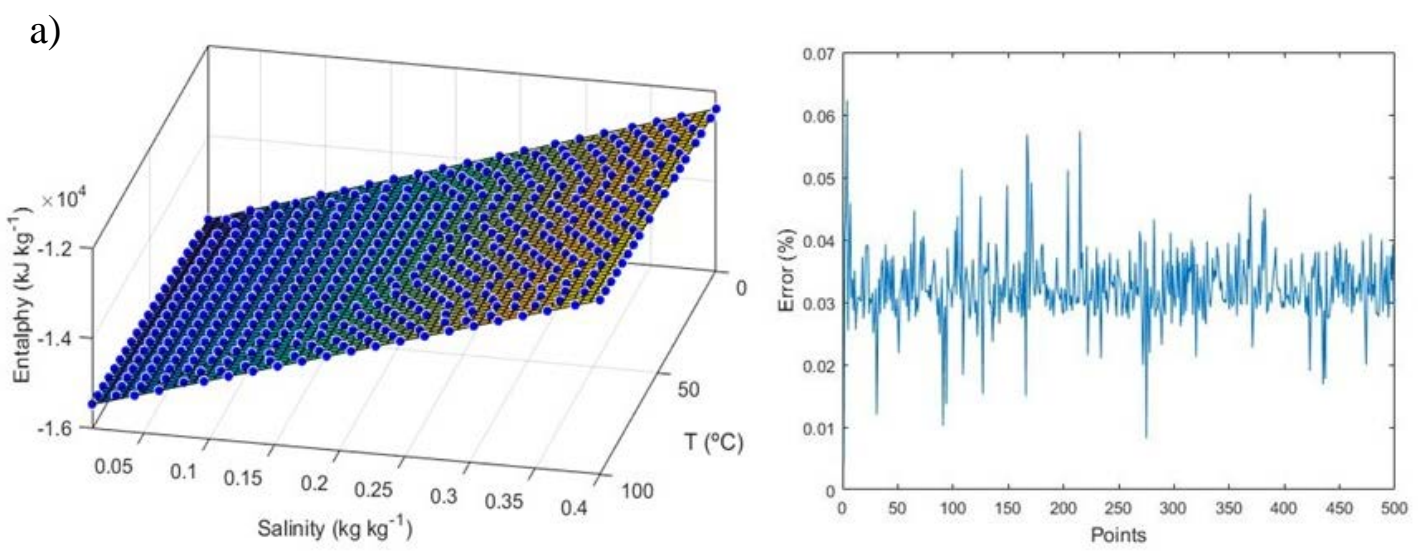

Fig. 4. (a) Surface plot of enthalpy as a function of salinity and temperature and (b) relative error.

The membrane area is calculated by Eq. (5).

$a_{n}^{\text {memb }} \cdot j_{n}=f_{n}^{\text {perm }} \quad \forall n \in N$

Where $j_{n}$ is the permeate flux throughout the membrane calculated as proposed by Elsayed et al. (2014). Detailed description is provided in the Appendix A, Section A.2. The heat transfer across each membrane, $q_{n}^{\text {memb }}$, is calculated by standard heat transfer models accounting the corresponding four contributions:

- Convection from the feed bulk to the membrane interface as expressed by Eq. (6).

$q_{n}^{m 1}=h t_{n}^{m 1} \cdot\left(t_{n}^{m e m b}-t_{n}^{m 1}\right) \quad \forall n \in N$

In which, $h t_{n}^{m 1}$ is the convective heat transfer coefficient given by the correlation described by Eq. (7) as a function of temperature and brine salinity. The produced water properties needed to calculate rigorously the convective heat transfer coefficient (density, viscosity, heat capacity and thermal conductivity) have been obtained from OLI’s software (OLI Systems, 2010) using the thermodynamic package for electrolytes. 
A. Carrero-Parreño et al.

The physical properties correlations have been generated by considering temperature ranging from $40{ }^{\circ} \mathrm{C}$ to $90{ }^{\circ} \mathrm{C}$, and brine salinity between 40 to $300 \mathrm{~g} \cdot \mathrm{kg}^{-1}$ water.

$$
h t_{n}^{m 1}=2.61-4.96 \cdot x_{n}^{m e m b}+0.03 \cdot t_{n}^{m e m b} \quad \forall n \in N
$$

- Conduction and water evaporation inside the membrane are given by Eq. (8).

$q_{n}^{m e m b}=h t_{n}^{\text {cond }} \cdot\left(t_{n}^{m 1}-t_{n}^{m 2}\right)+h v_{n} \cdot j_{n} \quad \forall n \in N$

$h v_{n}$ is the water latent heat of vaporization. The conduction heat transfer coefficient, $h t_{n}^{\text {cond }}$, is defined by Eq. (9).

$h t_{n}^{\text {cond }} \cdot E=k_{n} \quad \forall n \in N$

In which, $E$ is the thickness of the membrane and $k_{n}$ is its thermal conductivity given by the following correlation proposed by Elsayed et al. (2014), where $t_{n}$ is the average temperature between $t_{n}^{\text {memb }}$ and $t_{n}^{\text {perm }}$ :

$$
k_{n}=1.7 \cdot 10^{-7} \cdot t_{n}-4 \cdot 10^{-5} \quad \forall n \in N
$$

- Convection from the membrane interface to the permeate bulk is calculated by Eq. (11).

$$
q_{n}^{m 2}=h t_{n}^{m 2} \cdot\left(t_{n}^{m 2}-t_{n}^{p e r m}\right) \quad \forall n \in N
$$

In which, $h t_{n}^{m 2}$ is the convective heat transfer coefficient at the permeate side given by the correlation defined in Eq. (12). The same procedure detailed before for the calculation of the convective heat transfer coefficient at the feed side is used. In this 
A. Carrero-Parreño et al.

case, the water salinity in the permeate side is equal to zero (salt-free), and the temperature range is considered to vary from 20 to $90{ }^{\circ} \mathrm{C}$.

$$
h_{n}^{m 2}=0.004 \cdot t_{n}^{p e r m}+2.8 \quad \forall n \in N
$$

At steady state, the overall heat transfer flux must be balanced (Hitsov et al., 2015; Yun et al., 2006):

$q_{n}^{m 1}=q_{n}^{m e m b}=q_{n}^{m 2} \quad \forall n \in N$

To avoid inconsistent performance of the membrane modules and solutions without physical meaning, the following constraints that ensure suitable working conditions (i.e. outlet flow should not be higher than inlet flow) should be introduced in the model:

$$
\begin{aligned}
& f_{n}^{r e j} \leq f_{n}^{\text {memb }} \quad \forall n \in N \\
& f_{n}^{\text {conc }} \leq f_{n}^{r e j} \quad \forall n \in N \\
& t_{n}^{m 1} \leq t_{n}^{\text {memb }} \quad \forall n \in N \\
& t_{n}^{m 2} \leq t_{n}^{m 1} \quad \forall n \in N \\
& t_{n}^{\text {perm }} \leq t_{n}^{m 2} \quad \forall n \in N
\end{aligned}
$$

Finally, the following design specification is included to reach close to ZLD conditions at the end of the membrane system.

$$
x_{n}^{r e j} \geq X^{\text {zld }} \quad n=|N|
$$

\subsection{Design equations for the preheater, cooler and heat exchanger}

The energy required in the preheater is given by Eq. (20), 
A. Carrero-Parreño et al.

$q_{n}^{\text {preh }}=f_{n}^{\text {memb }} \cdot\left(h_{n}^{s}\left(t_{n}^{\text {memb }}, x_{n}^{\text {memb }}\right)-h_{n}^{s}\left(t_{n}^{h x, \text { out }}, x_{n}^{\text {memb }}\right)\right) \quad \forall n \in N$

where $t_{n}^{\text {memb }}$ and $t_{n}^{h x, \text { out }}$ are the inlet membrane temperature and the outlet heat exchanger temperature, respectively.

The heat transfer area is defined by the following equation:

$a_{n}^{\text {preh }} \cdot U^{\text {preh }} \cdot \operatorname{lmtd}_{n}^{\text {preh }}=q_{n}^{\text {preh }} \quad \forall n \in N$

where $U^{\text {preh }}$ is the overall heat transfer coefficient and $\operatorname{lmtd}_{n}^{\text {preh }}$ is the log mean temperature difference that is reformulated using Chen's approximation (Chen, 1987) to overcome the numerical difficulties created by the logarithm, in which, the temperature differences, $\theta$, are given by Eqs. (22-24).

$\operatorname{lmtd}_{n}^{\text {preh }}=\left(0.5 \cdot\left(\theta_{n}^{1} \cdot \theta_{n}^{2}\right)\left(\theta_{n}^{1}+\theta_{n}^{2}\right)\right)^{1 / 3} \quad \forall n \in N$

$\theta_{n}^{1}=T^{\text {steam }}-t_{n}^{\text {memb }} \quad \forall n \in N$

$\theta_{n}^{2}=T^{\text {steam }}-t_{n}^{\text {hx,out }} \quad \forall n \in N$

The temperature difference between shell and tubes must be greater than the design minimum difference temperature to allow effective heat transfer,

$$
\Delta T^{\text {min }} \leq T^{\text {steam }}-t_{n}^{\text {memb }} \quad \forall n \in N
$$


A. Carrero-Parreño et al.

$\Delta T^{\text {min }} \leq T^{\text {steam }}-t_{n}^{\text {hx,out }} \quad \forall n \in N$

The same procedure, which is detailed in Appendix A, is applied to design the heat exchanger and cooler.

\subsection{GDP formulation in membrane stages}

To determine the number of distillation stages present in the desalination system, the disjunction showed in Eq. (27) is introduced to formulate the decision of the existence of a stage. If the stage exists, the concentrate stream of the previous stage, $f_{n-1}^{\text {conc }}=f_{n}^{\text {feed }}$ , is equal to the inlet flowrate through stage $n, f_{n}^{\text {stage }}$ (see Fig.2). Otherwise, $f_{n}^{\text {stage }}$ is equal to zero and $f_{n}{ }^{\text {feed }}=f_{n}^{\text {bypass }}$. In this equation, the Boolean variable: $Y_{n}^{\text {stage }}$ will be «True» if the stage $n$ exists and «False», otherwise.

$$
\begin{aligned}
& {\left[\begin{array}{c}
Y_{n}^{\text {stage }} \\
F_{n}^{\text {stage }, \text { LO }} \leq f_{n}^{\text {stage }} \leq F_{n}^{\text {stage }, U P} \\
f_{n}^{\text {bypass }}=0
\end{array}\right] \vee\left[\begin{array}{c}
\neg Y_{n}^{\text {stage }} \\
F_{n}^{\text {bypass }, L O} \leq f_{n}^{\text {bypass }} \leq F_{n}^{\text {bypass }, U P} \\
f_{n}^{\text {stage }}=0
\end{array}\right] \forall n \in N} \\
& Y_{n}^{\text {stage }} \in\{\text { True,False }\}
\end{aligned}
$$

The previous disjunction can be reformulated into an MINLP model, by using the hull reformulation (Vecchietti et al., 2003) as follows:

$$
\begin{aligned}
& f_{n}^{\text {stage }} \leq F_{n}^{\text {stage }, U P} \cdot \mathrm{y}_{n}^{\text {stage }} \\
& f_{n}^{\text {stage }} \geq F_{n}^{\text {stage } L O} \cdot \mathrm{y}_{n}^{\text {stage }} \\
& f_{n}^{\text {bypass }} \leq F_{n}^{\text {bypass }, U P} \cdot\left(1-\mathrm{y}_{n}^{\text {stage }}\right) \\
& f_{n}^{\text {bypass }} \geq F_{n}^{\text {stage } L O} \cdot\left(1-\mathrm{y}_{n}^{\text {stage }}\right) \\
& y_{n}^{\text {stage }} \in\{1,0\}
\end{aligned}
$$

Some logical relationships (Eqs. 29 and 30) are included in the model, in terms of Boolean variables and their corresponding re-formulation to algebraic equations using 
A. Carrero-Parreño et al.

binary variables. See Raman and Grossmann (1994) for a detailed description of how to systematically transform logic propositions to algebraic equations.

Eq. 29 specifies that a membranes stage or a bypass must exist.

$$
Y_{n}^{\text {stage }} \underline{\vee} Y_{n}^{\text {bypass }} \quad \rightarrow \quad y_{n}^{\text {stage }}+y_{n}^{\text {bypass }}=1 \quad \forall n \in N
$$

If a bypass exists in stage $n$, then the bypass should also exist in all subsequent stages to avoid the non-existence of intermediate stages.

$$
Y_{n}^{\text {bypass }} \Rightarrow Y_{n+1}^{\text {bypass }} \quad \rightarrow \quad y_{n}^{\text {bypass }} \leq y_{n+1}^{\text {bypass }} \quad n<|N|
$$

\subsection{Objective function}

The objective function to be minimized corresponds to the total annualized cost (TAC) of the multistage MDS. The TAC comprises the contributions related to the annualized capital investment (CAPEX) of the equipment (including membrane modules and heat exchangers), and the annual operational expenses (OPEX) associated with the cost of membranes replacement, pumping, heating, and cooling:

$\min :$ tac $=$ capex $\cdot F+$ opex

In which, $F$ is the annualization factor as defined by (Smith, 2005):

$$
F \cdot\left((1+I)^{W}-1\right)^{-1}=I \cdot(1+I)^{W}
$$

where $I$ is the interest rate per year and $\mathrm{W}$ is the time horizon.

The capital expenditure includes the membrane cost $\left(C^{\text {memb }}\right)$ and the capital cost of the heat exchangers, which are calculated by the correlation proposed by Turton et al. 
(2012). All capital costs have been updated for the relevant year by the CEPCI index (Chemical Engineering Plant Cost Index).

$$
\text { capex } \left.=C^{\text {memb }} \cdot a_{n}^{\text {memb }}+F B M \cdot\left[114.79 \cdot\left(a_{n}^{\text {preh }}+a_{n}^{h x}+a_{n}^{\text {preh }}\right)+40,7914\right)\right]
$$

In Eq. (33), FBM corresponds to a correction factor which correlates the operating pressure with the construction material.

As aforementioned, the operational expenses (OPEX) include membrane replacement cost ( $C^{\text {replac }}$ ), considered to be equal to $15 \%$ of the capital cost per year; pumping cost ( $\left.C^{\text {pumps }}\right)$; heating cost $\left(C^{\text {steam }}\right)$; and cooling cost $\left(C^{\text {water }}\right)$.

$$
\begin{aligned}
\text { opex }=\sum_{n \in N} & C^{\text {memb }} \cdot a_{n}^{\text {memb }} \cdot C^{\text {replac }}+\left(C^{\text {steam }} \cdot f_{n}^{\text {steam }}+\right. \\
& \left.+C^{\text {pumps }} \cdot f_{n}^{\text {pumps }}+C^{\text {water }} \cdot q_{n}^{\text {cooler }}\right) \cdot W H
\end{aligned}
$$

In Eq. (34), WH is the working hours per year; $f_{n}^{\text {steam }}$ is calculated from the total energy required and the water heat of vaporization, and $f_{n}^{\text {pumps }}$ includes the process flows which need pumping.

\section{Case studies initial data}

Several case studies, based on real produced water data generated from the Marcellus shale formation, have been performed to evaluate the capabilities of the proposed mathematical model to optimize MDS applied to close to ZLD desalination of shale gas water.

The present work considers that the MDS has the capacity to treat the produced water generated by 3 wellpads of 12 wells each (Manda et al., 2014). Therefore, the input mass flowrate is equal to $2 \mathrm{~kg} \cdot \mathrm{s}^{-1}\left(7.22 \mathrm{~m}^{3} \cdot \mathrm{h}^{-1}\right)$, based on the maximum capacity per well (i.e $4.82 \cdot 10^{-2} \mathrm{~kg} \cdot \mathrm{s}^{-1}$ including $15 \%$ extra capacity). 
A. Carrero-Parreño et al.

The base case study considers Marcellus shale salinity of $200 \mathrm{~g} \cdot \mathrm{kg}^{-1}$ water since U.S. Environmental Protection Agency (2016) reported that produced water generated per well in the U.S ranges from $1.71 \cdot 10^{-2} \mathrm{~kg} \cdot \mathrm{s}^{-1}$ to $4.82 \cdot 10^{-2} \mathrm{~kg} \cdot \mathrm{s}^{-1}$ and Marcellus shale salinity average sampling data for 19 sites is $200 \mathrm{~g} \cdot \mathrm{kg}^{-1}$ water. Nevertheless, the produced water from different wells can have significant salinity differences depending on the shale gas formation. For this reason, sensitivity studies of the system behavior have been performed under different salt concentrations ranging from 150 to $250 \mathrm{~g} \cdot \mathrm{kg}^{-}$ ${ }^{1}$ water. The MDS outlet concentrate salinity has to be greater or equal than $300 \mathrm{~g} \cdot \mathrm{kg}^{-}$ ${ }^{1}$ water (i.e. close to salt saturation condition of $\sim 350 \mathrm{~g} \cdot \mathrm{kg}^{-1}$ water) to maximize the water recovery. Table 1 summarizes all the input data used in the case studies.

Table 1. Input data used in the model.

\section{Feed water}

Mass flowrate

Temperature

Membrane parameters

Thickness

Permeability

Output parameters

Outlet Salinity

\section{Cost Data}

Cooling water cost

Steam cost a

Membrane cost

Pumping cost

Factor of annualized capital

cost

Factor of annualized

\section{Source}

$7.22 \mathrm{~m}^{3} \cdot \mathrm{h}^{-1}\left(2 \mathrm{~kg} \cdot \mathrm{s}^{-1}\right)$

$20{ }^{\circ} \mathrm{C}$

$0.65 \mathrm{~mm}$

$5.610^{-3} \mathrm{~kg}\left(\mathrm{~m}^{2} \cdot \mathrm{Pa} \cdot \mathrm{h}\right)^{-1}$

$300 \mathrm{~g} \cdot \mathrm{kg}^{-1}$

$11.2 \mathrm{US} \$(\mathrm{~kW} \cdot \text { year })^{-1}$

$0.007 \mathrm{US} \$ \cdot \mathrm{kg}^{-1}$

90 US\$ $\mathrm{m}^{-2}$

$0.056 \mathrm{US}^{\mathrm{N}} \mathrm{m}^{-3}$
(Lira-Barragán et al., 2016)

(Onishi et al., 2017b)

\section{Source}

(Al-Obaidani et al., 2008)

(Lokare et al., 2017)

\section{Source}

(Onishi et al., 2017b)

\section{Source}

(Turton et al., 2012)

(Al-Obaidani et al., 2008)

(Al-Obaidani et al., 2008)

(Song et al., 2008)

0.13 (5\% - 10 year)

0.28 (5\% - 4 year) 
membrane capital cost

Additionally, in order to ensure that the system works within its operational limits, the following variables have been fixed or constrained: 1) the membrane inlet temperature is restricted between $40-90{ }^{\circ} \mathrm{C}$; 2) minimum temperature difference between the shell and tubes in the heat exchanger is equal to $10^{\circ} \mathrm{C}$; 3) cooler outlet temperature is fixed to $30{ }^{\circ} \mathrm{C}$ to allow sufficient difference of vapor pressure at both sides of the membrane (i.e. membrane driving force) and 4) the use of water as refrigerant fluid (i.e. other refrigerant fluids have been discarded due to their higher comparative price (Turton et al., 2012)).

In the following sections, the main results obtained are described.

\section{Results and discussion}

\subsection{Multistage membrane distillation design}

The resulting optimal MDS configuration for the base case, using Marcellus real shale salinity of $200 \mathrm{~g} \cdot \mathrm{kg}^{-1}$ water, consists of three MD stages with a total required membrane area of $603 \mathrm{~m}^{2}$ (225, 221 and $157 \mathrm{~m}^{2}$, respectively). Additionally, a recycle ratio (total recycle flowrate with respect to the feed flowrate) of 9 allows reaching the outlet salinity specification (i.e. $300 \mathrm{~g} \cdot \mathrm{kg}^{-1}$ water). The optimum configuration and the main process variables (i.e. areas, flows, temperatures, utilities, etc.) are shown in Fig. 5. 


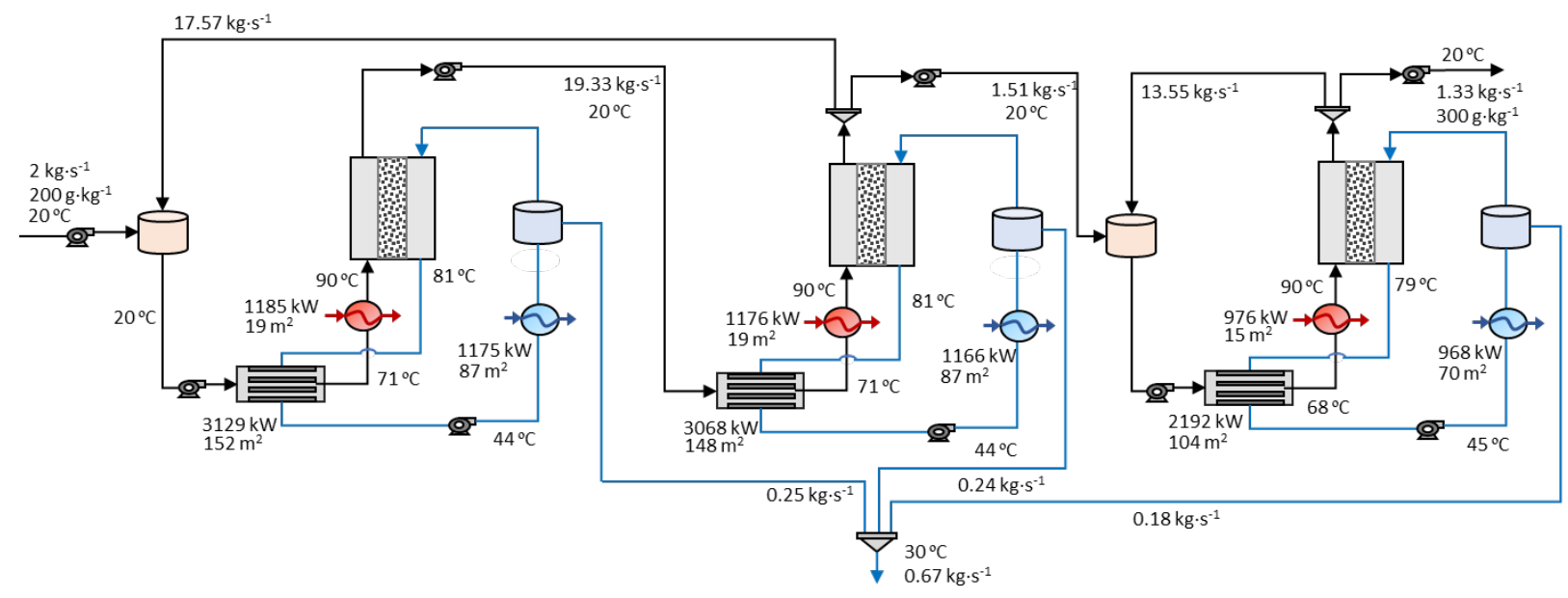

Fig. 5. Optimal solution of the multistage membrane distillation system (MDS) with heat integration obtained for the base case study.

The accuracy of the optimal solution obtained is verified using the commercial software Aspen HYSYS ${ }^{\circledR}$ (version 8.8) assuming steady state conditions and using the thermodynamic package NRTL-electrolytes. To simulate the MDS, the variables have been classified as process variables and design variables, being the design variables the input data needed to simulate the system (i.e. outlet temperature of heaters, coolers and heat exchangers, reject temperature and outlet salt concentration). A logical unit balance operation is used to simulate the energy and mass balances through the membrane. Appendix B, Fig. B.1 shows the MDS diagram in Aspen HYSYS ${ }^{\circledR}$ and Table B.1 the values of the process variables obtained from the mathematical model, from the simulation and the difference between them. For all variables, the differences found comparing both values are below $1 \%$.

The optimal MDS solution achieves a total annualized cost (TAC) of $523 \mathrm{kUS} \$$ year $^{-1}$, including 88 kUS\$ year ${ }^{-1}$ related to capital expenditure and $435 \mathrm{kUS \$}_{\text {year }}{ }^{-1}$ in operational expenses. Fig. 6 shows the fractional contribution of various cost elements for the optimal solution. As can be observed, TAC mayor contributor is the heating energy required by the system ( $62 \%$ ), followed by the pumping costs ( $12 \%)$. Since 
A. Carrero-Parreño et al.

high recycle ratios are needed to reach the outlet specified salinity and these streams must be reheated before entering the membrane stage again, the amount of thermal and pumping energy required increases dramatically. Similar findings were reported by Tavakkoli et al. (2017), in whose study most of the operational cost was attributed to the thermal energy requirements.

Optimal recycle configuration includes direct recycle in stage three while an inter-stage recycle between the second and first stages is established, obtaining the lowest overall recycle ratios.

To analyze the effect of the system configuration (i.e. the recycle connections and the number of MD stages) on the cost of the MDS, several cases have been solved varying these design variables.

Firstly, to study the influence of the recycle connections, the system has been solved predetermining different recycle configurations. The results for the CAPEX, OPEX and the heating cost, which is the maximum contribution to OPEX, are detailed in Table 2.

Table 2. Optimal costs (kUS\$ year ${ }^{-1}$ ) of MDS under different recycle connections.

\begin{tabular}{lccc}
\hline \multicolumn{1}{c}{ Recycle ratio configuration description } & CAPEX & OPEX & Heating cost \\
\hline Direct recycle in each stage & 88 & 452 & 310 \\
Inter-stage recycle from stage three to stage & 87 & 466 & 343 \\
one & & & \\
Inter-stage recycle from stage three to stage & 88 & 440 & 321 \\
two and direct recycle in stage one & & & \\
\hline
\end{tabular}

If only direct recycle is allowed, the total cost increases $17 \mathrm{kUS \$} \mathrm{year}{ }^{-1}$ with respect to the base case optimal solution. Considering inter-stage recycle from stage three to stage

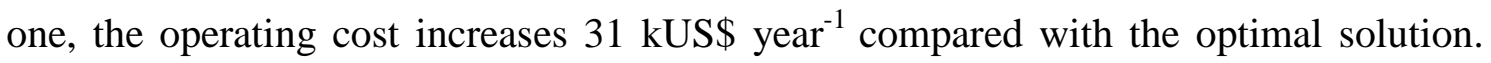


The solution of the last recycling possibility, inter-stage recycle from stage three to stage two and direct recycle in stage one, is only 5 kUS\$ year ${ }^{-1}$ higher than the optimal solution. In all these three cases, higher recycle ratios than the obtained for the optimal solution are needed, and consequently, the resulting operating costs are higher.

As said before, the influence of the number of membrane distillation stages is also analyzed to find out the process cost differences compared to the optimal solution. The results, shown in Fig. 7, highlight that defining fewer stages than those calculated for the optimal solution is less attractive since a higher TAC is obtained. Although in these configurations (1 or 2 stages) the capital expenditure decreases, the operating costs rise to a larger extent, thus causing the increase of the TAC. When fewer membrane stages are used, higher recycle ratios are needed, consequently, the heating and pumping costs increase. For instance, when considering only one stage, although the capital cost is lower (58 kUS\$ year ${ }^{-1}$ ) due to the fewer installed equipment, the operational cost is $15 \%$ higher than that in the optimal solution (500 kUS\$ year ${ }^{-1}$ ). On the contrary, the operational savings attained by adding more than three membranes do not compensate the capital cost increment (e.g., the capital cost is $132 \mathrm{kUS \$}$ year $^{-1}$ and the operational

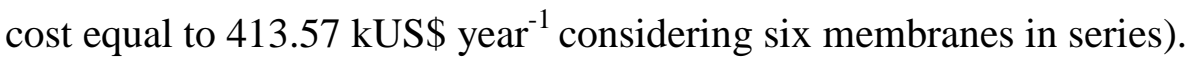


A. Carrero-Parreño et al.

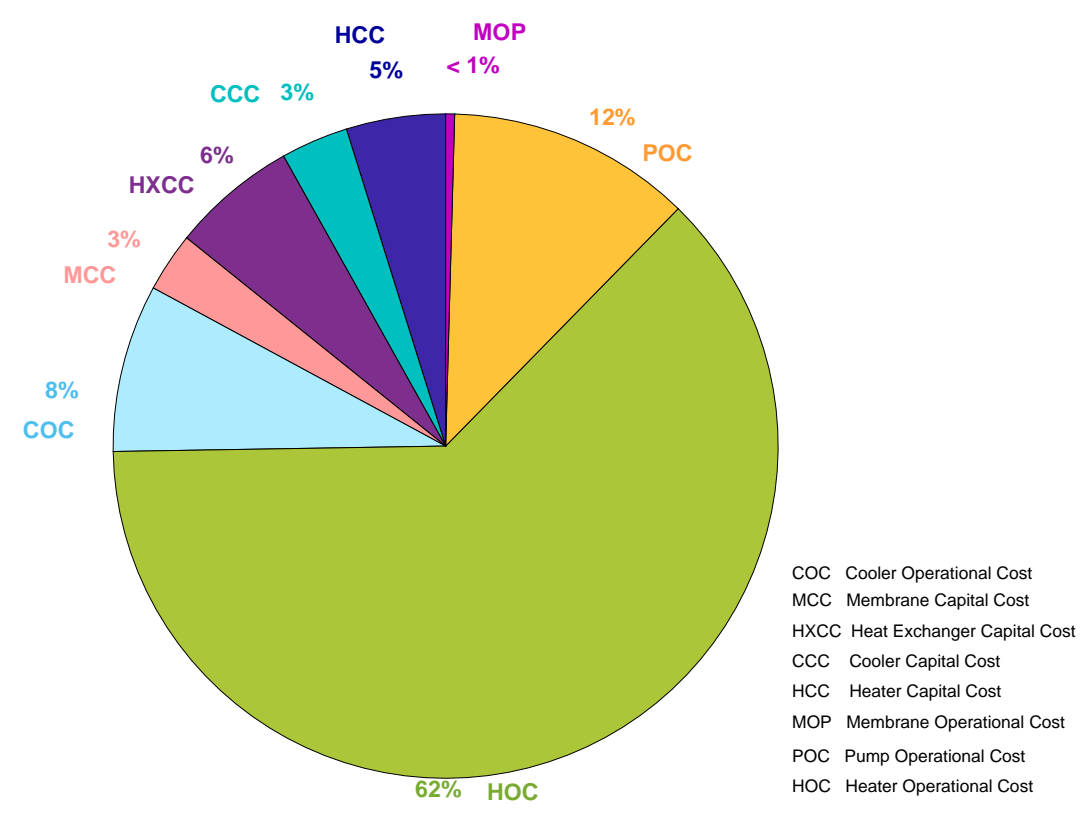

Fig. 6. Fractional contribution of various cost elements for the optimal solution of the base case study.

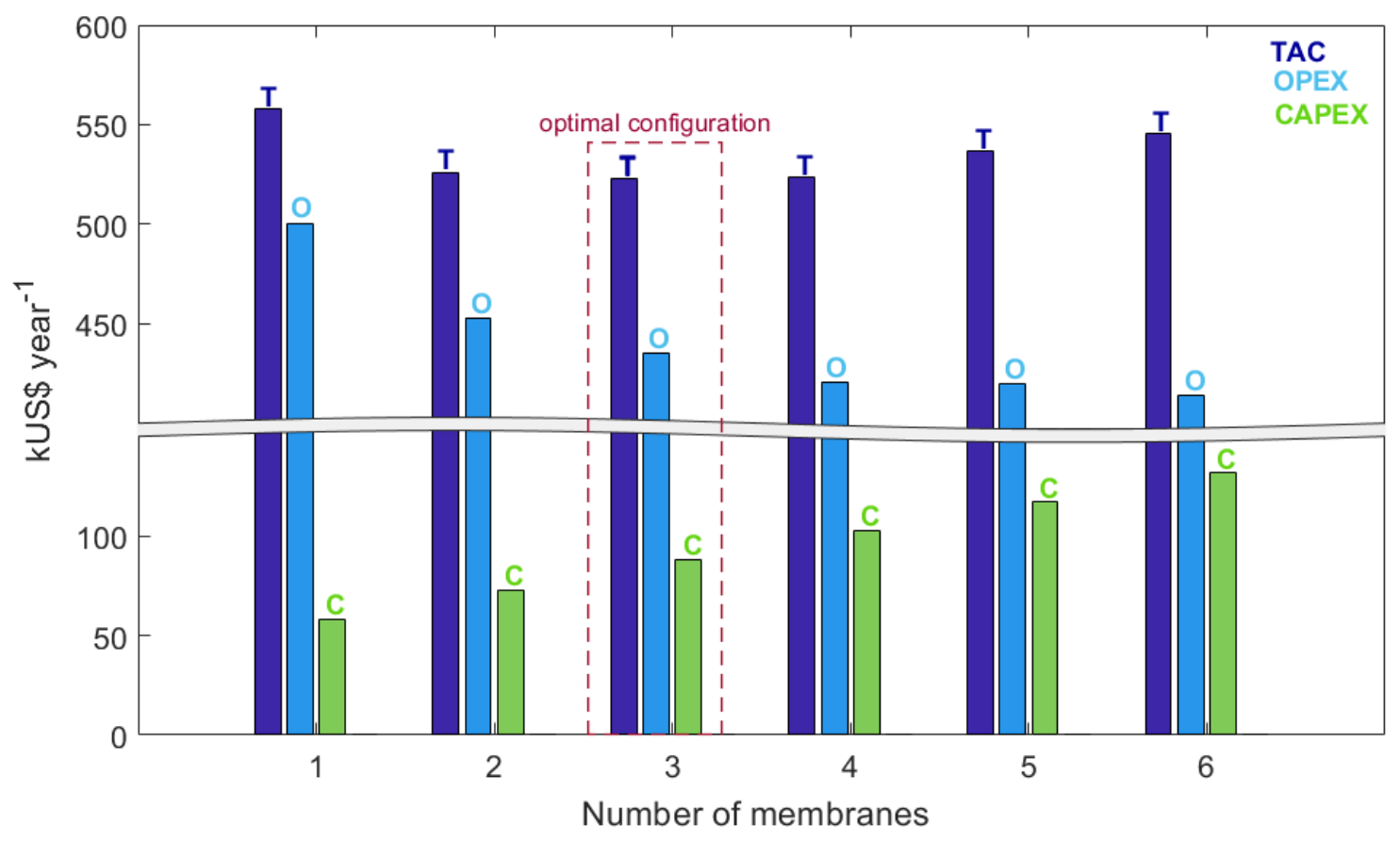

Fig. 7. Effect of the number of membrane stages in serires on the process cost.

\subsection{Parametric study of the impact of membrane fouling}

Membrane fouling is one of the major drawbacks in membrane technologies causing a severe flux decline, affecting the quality of the water and increasing the treatment costs. 
Assuming that fouling affects the membrane permeability, we have solved the model for different permeability. Specifically, we have studied its effect on the capital and operational costs by decreasing its value by $10 \%$, in a range from 90 to $50 \%$ of the permeability value used in the base case.

The results reveal that the TAC is slightly affected increasing the total cost by 8 kUS\$ year ${ }^{-1}$ comparing the base case with the worst situation (i.e. membrane permeability reduced by $50 \%$ ). As the flux through the membrane decreases, to satisfy the salt concentration outlet requirement, both total membrane area and heating required increase from 603 to $697 \mathrm{~m}^{2}$ and from to 3335 to $3379 \mathrm{~kW}$. Hence, the results indicate that the membrane fouling have not a significant impact to the thermal efficiency of the process.

\subsection{Parametric study of the effect of steam cost}

As aforementioned, the TAC is significantly affected by steam cost. Some works in literature have considered the use of inexpensive heat sources such as the waste heat of process facilities or flaring (Bamu et al., 2017; Elsayed et al., 2015; Elsayed et al., 2014; González-Bravo et al., 2017, 2015). That consideration is very attractive for membrane distillation where the separation occurs below the normal water boiling point.

Taking into account that the steam cost varies significantly depending on the location of the plant and country, in this section we study the impact of the steam cost on the system configuration and total process cost. We analyze the base case, which considers low-cost steam equal to US\$ $0.007 \mathrm{~kg}^{-1}$ (Al-Obaidani et al., 2008), and the extreme situations, considering a high-cost steam equal to US\$ $0.028 \mathrm{~kg}^{-1}$ (Turton et al., 2012) and free heating source. In the latter case, the heating cost is removed from the objective function since the energy is provided from waste heat of shale gas production. 
A. Carrero-Parreño et al.

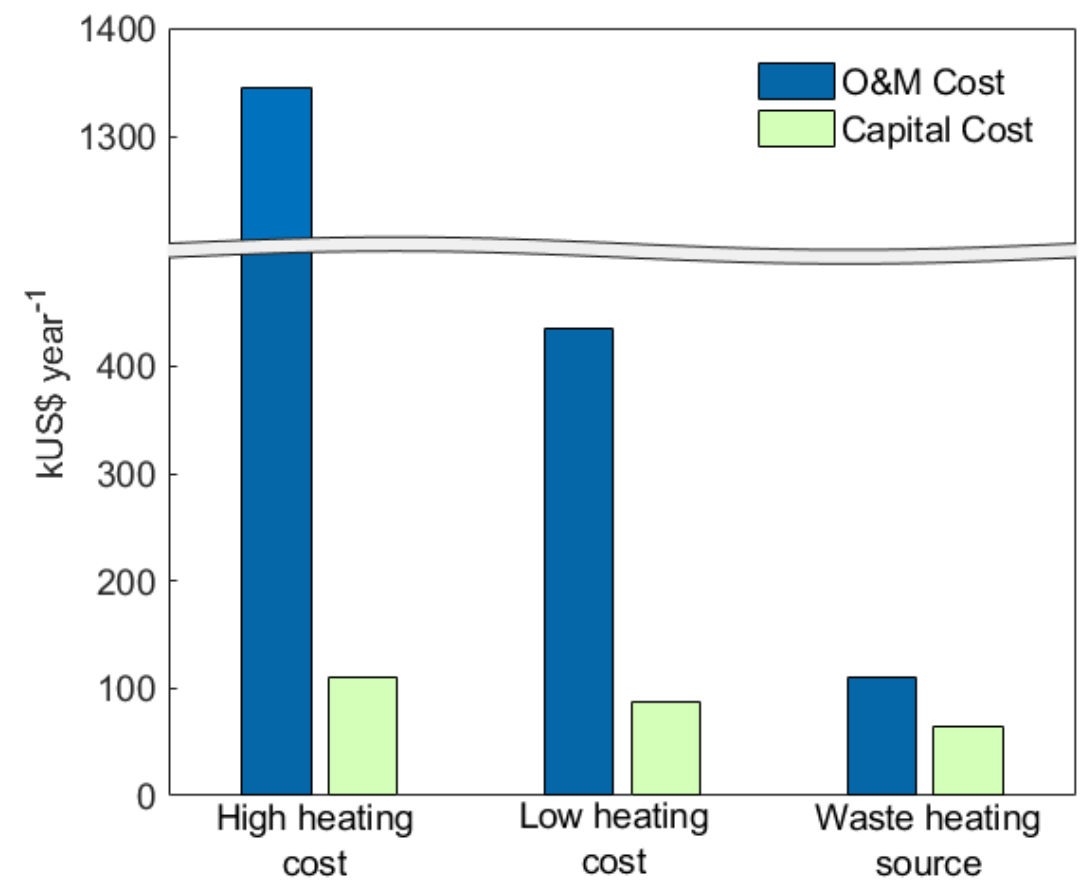

Fig. 8. Effect of steam cost on the total process cost for the optimal solution of the base case study.

Fig. 8 shows the capital and operation and maintenance (O\&M) costs for the optimal solution of the three considered situations for the steam cost (inlet salinity in maintained constant at $200 \mathrm{~g} \cdot \mathrm{kg}^{-1}$ water). The TAC of treating produced water is equal to 1546

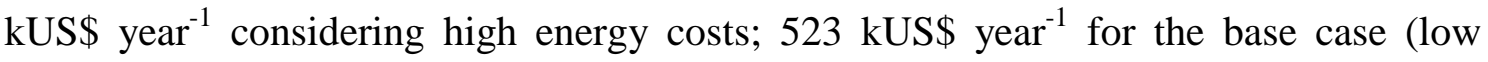
heating cost); and $174 \mathrm{kUS \$}$ year $^{-1}$ when energy is provided from waste heat of shale gas production. The operational expenses take the value of $1345 \mathrm{kUS} \$$ year $^{-1}$, $435 \mathrm{kUS \$}$ year $^{-1}$ and 65 kUS\$ year ${ }^{-1}$, respectively, which means that operational cost savings up to 95\% could be obtained depending on the heating source. Although clearly the cost savings are affected by the heating cost reduction, they also arise from the differences in the system configuration. As can be seen in Fig. 8, the capital expenses also decrease as the heating cost is lower, being the system configuration equal to four, three and two stages, respectively. This is due to the trade-off between the amount of water recycled and the number of membrane stages. The higher the number of membrane stages, the 
A. Carrero-Parreño et al.

lower recycle ratios are needed. Therefore, when the heating cost is low, it is more costeffective to preheat high recycle ratios than increase the number of membranes stages.

\subsection{Parametric study of the effect of produced water salinity}

The composition of the produced water is another uncertain parameter for designing MDS. It depends on the exploitation site and it varies also over the well lifetime.

In this section, the analysis of the optimal system configuration and economic performance of the system under different inlet salinities - ranging from 150 to 250 $\mathrm{g} \cdot \mathrm{kg}^{-1}$ water - is evaluated. Note that the outflow brine salinity remains up to $300 \mathrm{~g} \cdot \mathrm{kg}^{-1}$ water to achieve close to ZLD conditions and therefore, the maximum water recovery.

Fig. 9 shows the effect of the produced water salinity on treated water cost and desalinated water cost. In this figure, it is possible to observe that the treated water cost decreases when the inlet salinity increases, changing from 11.54 to 4.4227 US\$ per cubic meter of inlet water. This reduction in process costs occurs since, as the concentrations of inlet and outlet streams are more similar, less energy is needed to achieve the outflow stream near saturation conditions. Note that equipment size and the number of membrane modules are also reduced for treating feed water with higher TDS contents. For instance, the total membrane area for the MDS configuration, for the extreme salt concentrations (i.e., inlet concentration of $150 \mathrm{~g} \cdot \mathrm{kg}^{-1}$ water and $250 \mathrm{~g} \cdot \mathrm{kg}^{-}$ ${ }^{1}$ water), decreases from $925 \mathrm{~m}^{2}$ to $295 \mathrm{~m}^{2}$, correspondingly. Also, in the case of inlet salinity equal to $150 \mathrm{~g} \cdot \mathrm{kg}^{-1}$ water, an optimal solution of four MD stages is obtained, while only two MD stages are required to achieve the desired outlet condition with the highest inlet salinity (250 $\mathrm{g} \cdot \mathrm{kg}^{-1}$ water).

It is worth mentioning that, the recovered water production rate is reduced when considering higher feed water salinities. The water recovered when the inlet salinity is significantly high (250 $\mathrm{g} \cdot \mathrm{kg}^{-1}$ water), decreases $67 \%$ comparing with the water 
A. Carrero-Parreño et al.

recovered when the inlet salinity is equal to $150 \mathrm{~g} \cdot \mathrm{kg}^{-1}$ water, thus increasing the amount of brine to be disposed. Hence, although the cost per cubic meter of inlet water decreases, the same cost expressed in terms of cost per cubic meter of permeate increases, changing from just over 23 US\$ per cubic meter of water generated in the process to nearly 27 US\$ per cubic meter. This trend agrees with works published by Elsayed, N et al. (2015) and Tavakkoli et al. (2017).

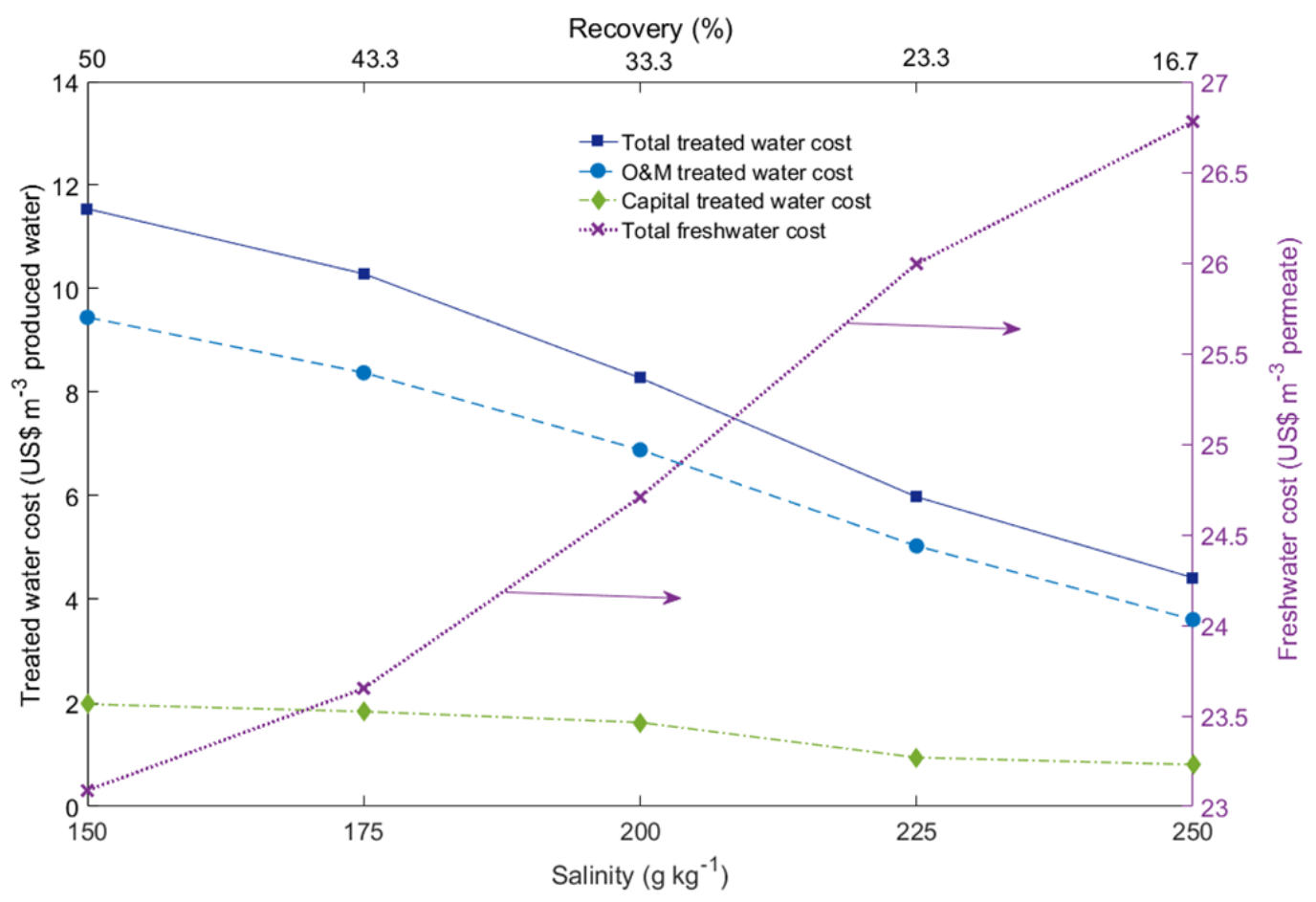

Fig. 9. Comparative effect of produced water salinity and water recovery on water treatment cost and freshwater cost of the multistage membrane distillation system.

\subsection{Membrane distillation feasibility for treating shale gas produced water.}

Previous sections highlighted the applicability of MDS to desalinate produced water to reach conditions close to ZLD. Nevertheless, the results indicate that the source of uncertainties such as the available heat source and inlet salinity conditions impact significantly the economic feasibility and configuration of MDS. 
A. Carrero-Parreño et al.

Without a low-cost steam source or waste heat available, the heating costs associated to obtain high permeate flux are significantly high. Whereas the steam source is usually known before deciding the selection of MDS as desalination technology, the reliability of the MDS design relies on the accuracy of the predicted value for the inlet salinity. On the one hand, if the MDS is designed for the worst case of the inlet salinity (lowest forecast value), the system will always satisfy the imposed specific salinity outlet conditions. However, this design would be at the expense of a high initial capital investment that might not be worthwhile if the real value (once the uncertainty is revealed) of the inlet salinity is significantly higher than the worst case value. On the other hand, a design of the MDS considering the mean forecast value requires a lower capital expenditure than the previous situation. Nevertheless, the specific outlet salinity may not be attained if the feed concentration is below the mean value.

As commented above, a comparison between the proposed MDS and a conventional thermal desalination technology used in shale gas operations, such as MEE-MVR (Silva et al., 2017) has been carried out. Onishi et al. (2017b) reported an optimal MEE-MVR treatment cost of $3.8 \mathrm{US} \$ \mathrm{~m}^{-3}$ of inlet water for an inlet salinity of $220 \mathrm{~g} \cdot \mathrm{kg}^{-1}$ water and inlet flowrate of $10.42 \mathrm{~kg} \cdot \mathrm{s}^{-1}$. As the MEE-MVR was designed for a higher flow rate, the treated cost is updated using the equation of the effect of the capacity on the equipment defined by Turton et al., 2012. Table 3.3 summarizes the treated water cost obtained with both technologies considering three different inlet water salinity and inlet flow equal to $2 \mathrm{~kg} \cdot \mathrm{s}^{-1}$.

Table 3. Treated water cost to desalinate shale gas water using MEE-MVR and MDS* (US\$ per cubic meter shale gas water).

\begin{tabular}{|c|c|c|c|}
\hline \multirow[t]{2}{*}{$\begin{array}{l}\text { Shale gas water } \\
\text { salinity }\left(\mathrm{g} \cdot \mathrm{kg}^{-1}\right)\end{array}$} & \multirow[t]{2}{*}{ MEE-MVR** } & \multicolumn{2}{|c|}{ MDS } \\
\hline & & Low heating & Waste heating \\
\hline
\end{tabular}


A. Carrero-Parreño et al.

\begin{tabular}{llcc} 
& & cost & source \\
\hline 70 & 9.9 & 15.4 & 5.5 \\
150 & 9.4 & 12.4 & 4.1 \\
200 & 7.8 & 8.2 & 2.7 \\
\hline * & &
\end{tabular}

* Results obtained by specifying brine salinity levels near to salt saturation concentration (i.e., $300 \mathrm{~g} \mathrm{~kg}^{-1}$ ) and inlet flow equal to $2 \mathrm{~kg} \cdot \mathrm{s}^{-1}$.

$* *$ Updated cost using the equation of the effect of the capacity on the equipment defined by Turton et al., 2012

Clearly, if only heating source at high cost is available, MEE-MVR should be selected since the cost is significantly lower. If low heating cost is accessible, the decision is not trivial. Although the treated water cost using MD is higher than that obtained with MEE-MVR, it must be emphasized that the difference is smaller as the salinity increases. Additionally, as mentioned in the introduction section, it should be considered that nowadays flowback water, which salinity is lower, is directly reused to fracture other wells. Then, the water treated for discharge will be produced water (inlet salinity higher than $150 \mathrm{~g} \cdot \mathrm{kg}^{-1}$ water). Another important point that can influence the decision is that MEE-MVR requires a continuous electrical supply such as a power grid, which could be limited or unavailable in remote shale gas extraction sites. Besides, specialized equipment, such as electrical-driven compressors or flash tanks, is necessary. On the contrary, the inherent modular nature of MD is advantageous for produced water treatment, since its compactness and mobility facilitate the installation of small desalination plants near remote extraction sites. Moreover, MD can operate using low-grade industrial steam that can be easily obtained in shale gas operations from waste heat recovered from the process facilities or flaring. Additionally, the treating cost of MD using waste heat is approximately half of the cost obtained using MEE-MVR (see Table 3.3).

As shown in previous sections, the shale gas produced water treatment cost is very sensitive to many factors such as inlet and outlet conditions or heating cost. This fact, coupled with the lack of standardized methodologies for cost calculations, hinders the 
A. Carrero-Parreño et al.

economic comparison between MDS and other desalination technologies applied to this type of high salinity wastewater.

\section{Computational aspects}

The MINLP problem has 6 binary variables, 265 continuous variables and 311 constraints (263 equalities). The proposed MINLP model is implemented in GAMS software (version 24.7.1) and solved on a computer with a $3 \mathrm{GHz}$ Intel Zeon Processor and 32 GB RAM running Windows 10. The solver ANTIGONE is used to optimize the problem. ANTIGONE is a deterministic mixed-integer non-linear-based global optimizer able to obtain global solution even for highly nonlinear and nonconvex character problems as the ones solved in this work. The problem required a CPU time of 628 s with $0 \%$ optimality gap. It should be highlighted that the bounds of all variables and good starting point are essential to solve the mathematical problem. As initial values we took the solution obtained solving the model fixing the structure of the system (i.e. the number of stages). 
A. Carrero-Parreño et al.

\section{Conclusions}

The present work highlights the potential for designing and deploying membrane distillation systems to treat shale gas produced water with high salt concentration. For this purpose, a multistage membrane distillation system (MDS) superstructure with energy recovery is modeled using the GDP framework as a MINLP problem in the GAMS modelling language. Then, this model is optimized to minimize the total annualized cost (TAC) of the system subject to the zero liquid discharge (ZLD) condition (i.e., a concentrate stream close to salt saturation conditions), which guarantees the maximum water recovery. It is worth noting that improving the costeffectiveness of the process by reducing brine discharges decreases the water footprint associated with the shale gas production.

As a result, an optimal full-scale membrane distillation is designed to desalinate wastewater from shale gas operations by establishing the number of membrane modules in series, the size of heat exchangers, and the system operating conditions. Note also, the high complexity of the model, since the mass flowrates and temperatures of the streams are decision variables, and many of the equations that define the problem are non-convex and non-linear.

The results obtained emphasize the applicability of this promising technology, especially when a low-cost energy source or waste heat are available. The treatment cost varies significantly depending on the energy cost since it represents more than $50 \%$ of the total annualized cost. For example, the cost per cubic meter of treated water is 23.0 $\mathrm{m}^{-3}$ US\$ for high energy costs; $8.3 \mathrm{~m}^{-3}$ US\$ for low energy costs; and $2.8 \mathrm{~m}^{-3}$ US\$ when energy is provided from waste heat of shale gas production.

Additionally, due to the uncertain salinity forecast of produced water, the reliability of the model has been checked by a sensitivity analysis carried out by varying the TDS 
A. Carrero-Parreño et al.

concentration from 150 to $250 \mathrm{~g} \mathrm{~kg}^{-1}$ water. The results reveal that the optimal configuration and the treatment cost depend significantly on the inlet salinity. Both the number of membrane stages and the total cost decrease as the inlet salinity increases. For the lowest value of salinity used in the analysis (i.e., $150 \mathrm{~g} \mathrm{~kg}^{-1}$ water), a cost of 11.5 US $\$ \mathrm{~m}^{-3}$ of inlet water is obtained with a system configuration composed of four membrane stages. On the contrary, for the highest salinity value (i.e., $250 \mathrm{~g} \mathrm{~kg}^{-1}$ water) both the cost and the number of membranes in the system decrease to 4.4 US $\$ \mathrm{~m}^{-3}$ of inlet water and two stages, respectively. Although the solutions considering higher feed water salinities are more cost effective, they have an important drawback for the water footprint of the shale gas exploitation activity. That is the low permeate flux of the MD process, which implies that only a small fraction of the huge amount of wastewater for the gas production is recovered.

The proposed model intends to be a systematic tool to guide the decision-maker towards the most cost-effective MDS design for this particular application. Although other economic analyses of MD applied to shale gas wastewater can be found in the literature, to the best of our knowledge, this is the first one that develops an MDS mathematical model coupled with heat recovery to determine the optimal design of the multistage structure and inter-stage recycling for several initial conditions obtaining the minimum cost.

Additionally, although MDS can be economically advantageous in remote areas where waste heat or low-grade thermal energy is available, and despite the advances made in the study of MD process, more laboratory analysis and pilot scale tests are still necessary to make this technology commercially attractive for shale gas wastewater desalination processes. 
A. Carrero-Parreño et al.

Further development of this work includes the design of multistage MDS coupled with solar thermal systems to find a robust design that ensures the optimal economic performance of the process during its entire lifetime whether there is enough, little or no waste energy available.

\section{ACKNOWLEDGMENTS}

This project has received funding from the European Union’s Horizon 2020 Research and Innovation Program under grant agreement No. 640979.

\section{NOMENCLATURE}

\section{Roman letters}

$\begin{array}{ll}a & \text { Area, } \mathrm{m}^{2} \\ B & \text { Membrane permeability, } \mathrm{kg}\left(\mathrm{m}^{2} \cdot \mathrm{Pa} \cdot \mathrm{h}\right)^{-1} \\ \text { CAPEX } & \text { Capital cost, } \mathrm{kUS} \$ \mathrm{year}^{-1} \\ h & \text { Specific enthalpy, } \mathrm{kJ} \cdot \mathrm{kg}^{-1} \\ f & \text { Mass flowrate, } \mathrm{kg} \mathrm{s}^{-1} \\ F & \text { Annualized capital cost factor } \\ h t & \text { Heat transfer coefficient, W } \mathrm{m}^{-2} \mathrm{~K}^{-1} \\ h v & \text { Latent heat of vaporization of water, } \mathrm{kJ} \mathrm{kg}^{-1} \\ I & \text { Fractional interest rate per year } \\ j & \text { Vapor flux through the membrane, } \mathrm{kg} \mathrm{m}^{-2} \mathrm{~h}^{-1} \\ \text { lmtd } & \text { Logarithmic mean temperature difference } \\ W & \text { Horizon time, year }\end{array}$


OPEX

$$
p
$$

$q$

$t$

$U$

WH

$X$

$\mathrm{y}$

Y

Superscripts

conc

cond

$h x$

$L O$

$m 1$

$m 2$

memb

perm

rec

refrig

rej

$U P$

Subscripts

$n$
Operational cost, kUS\$ year ${ }^{-1}$

Pressure, $\mathrm{Pa}$

Heat flow, kW

Temperature, ${ }^{\circ} \mathrm{C}$

Overall heat transfer coefficient, $\mathrm{kW}\left(\mathrm{m}^{2}{ }^{\circ} \mathrm{C}\right)^{-1}$

Working hours in one year, $\mathrm{h}$

Salt mass fraction

Binary variable

Boolean variable

Concentrate

Conduction

Heat exchanger

Lower bound

Membrane feed side

Membrane permeate side

Membrane

Permeate

Recirculated

Refrigerant

Reject

Upper bound

Membrane stage 
A. Carrero-Parreño et al.

Acronyms

CWT Centralized Water Treatment

DCMD Direct Contact Membrane Distillation

GAMS General Algebraic Modelling System

GDP Generalized Disjunctive Programming

MD Membrane Distillation

MDS

Membrane Distillation System

MEE-MVR

Multiple-Effect Evaporation with Mechanical Vapor

Recompression

MINLP

Mixed-Integer Nonlinear Programming

TAC

Total annualized cost

$\mathrm{RO}$

Reverse Osmosis

TDS

Total Dissolved Solids

ZLD

Zero Liquid Discharge

Greek letters

$\theta$

Temperature difference, ${ }^{\circ} \mathrm{C}$

Activity coefficient of the water

$\omega$

Salt molar fraction

\section{REFERENCES}

Al-Obaidani, S., Curcio, E., Macedonio, F., Di Profio, G., Al-Hinai, H., Drioli, E., 2008. Potential of membrane distillation in seawater desalination: Thermal efficiency, sensitivity study and cost estimation. J. Memb. Sci. 323, 85-98. doi:10.1016/j.memsci.2008.06.006 
A. Carrero-Parreño et al.

Ashoor, B.B., Mansour, S., Giwa, A., Dufour, V., Hasan, S.W., 2016. Principles and applications of direct contact membrane distillation ( DCMD ): A comprehensive review. Desalination 398, 222-246. doi:10.1016/j.desal.2016.07.043

Bamu, H., Abdelhady, F., Baaqeel, H.M., El-halwagi, M.M., 2017. Optimization of multi-effect distillation with brine treatment via membrane distillation and process heat integration. Desalination 408, 110-118. doi:10.1016/j.desal.2017.01.016

Carrero-Parreño, A., Onishi, V.C., Salcedo-Díaz, R., Ruiz-Femenia, R., Fraga, E.S., Caballero, J.A., Reyes-Labarta, J.A., 2017. Optimal Pretreatment System of Flowback Water from Shale Gas Production. Ind. Eng. Chem. Res. 56, 4386-4398. doi:10.1021/acs.iecr.6b04016

Chafidz, A., Kerme, E.D., Wazeer, I., Khalid, Y., Ajbar, A., Al-Zahrani, S.M., 2016. Design and fabrication of a portable and hybrid solar-powered membrane distillation system. J. Clean. Prod. 133, 631-647. doi:10.1016/J.JCLEPRO.2016.05.127

Chen, J.J.J., 1987. Comments on improvements on a replacement for the logarithmic mean. Chem. Eng. Sci. 42, 2488-2489. doi:10.1016/0009-2509(87)80128-8

Department of Enegy \& Climate Change, 2013. The Unconventional Hydrocarbon Resources of Britain’'S Onshore Basins - Shale Gas, Promote UK 2013.

Deshmukh, A., Boo, C., Karanikola, V., Lin, S., Straub, A.P., Tong, T., Warsinger, D.M., Elimelech, M., 2018. Membrane distillation at the water-energy nexus: limits, opportunities, and challenges. Energy Environ. Sci. doi:10.1039/C8EE00291F

Drioli, E., Ali, A., Macedonio, F., 2015. Membrane distillation: Recent developments and perspectives. Desalination 356, 56-84. doi:10.1016/j.desal.2014.10.028

Duong, H.C., Cooper, P., Nelemans, B., Cath, T.Y., Nghiem, L.D., 2015. Optimising 
A. Carrero-Parreño et al.

thermal efficiency of direct contact membrane distillation by brine recycling for small-scale seawater desalination. Desalination 374, 1-9. doi:10.1016/j.desal.2015.07.009

Elsayed, N., Barrufet, M., Eljack, F., El-Halwagi, M. 2015. Optimal Design of Thermal Membrane Distillation Systems for the Treatment of Shale Gas Flowback Water. Int. J. Membr. Sci. Technol. 2, 1-9. doi:10.15379/2410-1869.2015.02.02.01

Elsayed, N.A., Barrufet, M.A., El-Halwagi, M., 2014. Integration of thermal membrane distillation networks with processing facilities. Ind. Eng. Chem. Res. 53, 52845298. doi:10.1021/ie402315z

González-Bravo, R., Elsayed, N.A., Ponce-Ortega, J.M., Nápoles-Rivera, F., ElHalwagi, M.M., 2015. Optimal design of thermal membrane distillation systems with heat integration with process plants. Appl. Therm. Eng. 75, 154-166. doi:10.1016/j.applthermaleng.2014.09.009

González-Bravo, R., Ponce-Ortega, J.M., El-Halwagi, M.M., 2017. Optimal Design of Water Desalination Systems Involving Waste Heat Recovery. Ind. Eng. Chem. Res. acs.iecr.6b04725. doi:10.1021/acs.iecr.6b04725

Hammond, G.P., O’Grady, Á., 2017. Indicative energy technology assessment of UK shale gas extraction. Appl. Energy 185, 1907-1918. doi:10.1016/j.apenergy.2016.02.024

Hitsov, I., Maere, T., De Sitter, K., Dotremont, C., Nopens, I., 2015. Modelling approaches in membrane distillation: A critical review. Sep. Purif. Technol. 142, 48-64. doi:10.1016/j.seppur.2014.12.026

Jacquet, J.B., 2014. Review of risks to communities from shale energy development. Environ. Sci. Technol. 48, 8321-8333. doi:10.1021/es404647x

Kim, J., Kwon, H., Lee, S., Lee, S., Hong, S., 2017. Membrane distillation (MD) 
A. Carrero-Parreño et al.

integrated with crystallization (MDC) for shale gas produced water (SGPW) treatment. Desalination 403, 172-178. doi:10.1016/j.desal.2016.07.045

Lawson, K.W., Lloyd, D.R., 1996. Membrane distillation. I. Module design and performance evaluation using vacuum membrane distillation. J. Memb. Sci. 120, 111-121. doi:10.1016/0376-7388(96)00140-8

Lira-Barragán, L.F., Ponce-Ortega, J.M., Guillén-Gosálbez, G., El-Halwagi, M.M., 2016. Optimal Water Management under Uncertainty for Shale Gas Production. Ind. Eng. Chem. Res. 55, 1322-1335. doi:10.1021/acs.iecr.5b02748

Lokare, O.R., Tavakkoli, S., Khanna, V., Vidic, R.D., 2018. Importance of feed recirculation for the overall energy consumption in membrane distillation systems. Desalination 428, 250-254. doi:10.1016/j.desal.2017.11.037

Lokare, O.R., Tavakkoli, S., Rodriguez, G., Khanna, V., Vidic, R.D., 2017. Integrating membrane distillation with waste heat from natural gas compressor stations for produced water treatment in Pennsylvania. Desalination 413, 144-153. doi:10.1016/j.desal.2017.03.022

Lokare, O.R., Tavakkoli, S., Wadekar, S., Khanna, V., Vidic, R.D., 2017. Fouling in direct contact membrane distillation of produced water from unconventional gas extraction. J. Memb. Sci. 524, 493-501. doi:10.1016/j.memsci.2016.11.072

Manda, A.K., Heath, J.L., Klein, W.A., Griffin, M.T., Montz, B.E., 2014. Evolution of multi-well pad development and influence of well pads on environmental violations and wastewater volumes in the Marcellus shale (USA). J. Environ. Manage. 142, 36-45. doi:10.1016/j.jenvman.2014.04.011

OLI Systems, I., 2010. OLI ESP User Guide - A guide to using OLI ESP 8.2.

Onishi, V.C., Carrero-Parreño, A., Reyes-Labarta, J.A., Fraga, E.S., Caballero, J.A., 2017a. Desalination of shale gas produced water: A rigorous design approach for 
A. Carrero-Parreño et al.

zero-liquid discharge evaporation systems. J. Clean. Prod. 140, 1399-1414. doi:10.1016/j.jclepro.2016.10.012

Onishi, V.C., Carrero-Parreño, A., Reyes-Labarta, J.A., Ruiz-Femenia, R., SalcedoDíaz, R., Fraga, E.S., Caballero, J.A., 2017b. Shale gas flowback water desalination: Single vs multiple-effect evaporation with vapor recompression cycle and thermal integration. Desalination 404, 230-248. doi:10.1016/j.desal.2016.11.003

Raman, R., Grossmann, I.E., 1994. Modelling and computational techniques for logic based integer programming. Comput. Chem. Eng. 18, 563-578. doi:10.1016/00981354(93)E0010-7

Rosenthal, R.E., 2016. GAMS — A User ’s Guide. GAMS Doc. 24.6. 1-316.

Ruyle, B., Fragachan, F.E., 2015. Quantifiable Costs Savings by Using 100 \% Raw Produced Water in, in: SPE Latin American and Caribbean Petroleum Engineering Conference. Ecuador, p. 7.

Salcedo-Díaz, R., Ruiz-Femenia, R., Carrero-Parreño, A., Onishi, V.C., Reyes-Labarta, J.A., Caballero, J.A., 2017. Combining Forward and Reverse Osmosis for Shale Gas Wastewater Treatment to Minimize Cost and Freshwater Consumption, in: Computer Aided Chemical Engineering 40. pp. 2725-2730. doi:10.1016/B978-0444-63965-3.50456-6

Shaffer, D.L., Arias Chavez, L.H., Ben-sasson, M., Romero-Vargas Castrillón, S., Yip, N.Y., Elimelech, M., Sha, D.L., Chavez, L.H.A., Ben-sasson, M., Castrillo, S.R., 2013. Desalination and Reuse of High-Salinity Shale Gas Produced Water: Drivers, Technologies, and Future Directions. Environ. Sci. Technol. 47, 9569-83. doi:10.1021/es401966e

Silva, T.L.S., Morales-Torres, S., Castro-Silva, S., Figueiredo, J.L., Silva, A.M.T., 
A. Carrero-Parreño et al.

2017. An overview on exploration and environmental impact of unconventional gas sources and treatment options for produced water. J. Environ. Manage. 200, 511-529. doi:10.1016/j.jenvman.2017.06.002

Smith, R.M., 2005. Chemical Process Design and Integration. John Wiley and Sons, University of Manchester.

Song, L., Ma, Z., Liao, X., Kosaraju, P.B., Irish, J.R., Sirkar, K.K., 2008. Pilot plant studies of novel membranes and devices for direct contact membrane distillationbased desalination. J. Memb. Sci. 323, 257-270. doi:10.1016/j.memsci.2008.05.079

Swaminathan, J., Chung, H.W., Warsinger, D.M., Lienhard, J.H., 2016. Simple method for balancing direct contact membrane distillation. Desalination 383, 53-59. doi:10.1016/j.desal.2016.01.014

Tavakkoli, S., Lokare, O.R., Vidic, R.D., Khanna, V., 2017. A techno-economic assessment of membrane distillation for treatment of Marcellus shale produced water. Desalination 416, 24-34. doi:10.1016/j.desal.2017.04.014

Trespalacios, F., Grossmann, I.E., 2014. Review of Mixed-Integer Nonlinear and Generalized Disjunctive Programming Methods. Chemie Ing. Tech. 86, 991-1012. doi:10.1002/cite.201400037

Turton, R., Bailie, R.C., Whiting, W.B., Shaeiwitz, J.A., Bhattacharyya, D., 2012. Analysis, Synthesis , and Design of Chemical Processes, Fourth. ed. Prentice Hall. U.S. Energy Information Administration, 2017. Annual Energy Outlook 2017. URL http://www.eia.gov/outlooks/aeo (accessed 3.12.18).

U.S. Environmental Protection Agency, 2016. Technical Development Document For Effluent Limitations Guidelines and Standars for the Oil and Gas Extraction Point Source Category. Washington, DC. 
A. Carrero-Parreño et al.

Vecchietti, A., Lee, S., Grossmann, I.E., 2003. Modeling of discrete/continuous optimization problems: characterization and formulation of disjunctions and their relaxations. Comput. Chem. Eng. 27, 433-448. doi:10.1016/S00981354(02)00220-X

Yang, L., Grossmann, I.E., Manno, J., 2014. Optimization models for shale gas water management. AIChE J. 60, 3490-3501. doi:10.1002/aic.14526

Yun, Y., Ma, R., Zhang, W., Fane, A.G., Li, J., 2006. Direct contact membrane distillation mechanism for high concentration $\mathrm{NaCl}$ solutions. Desalination 188, 251-262. doi:10.1016/j.desal.2005.04.123 
A. Carrero-Parreño et al.

\section{Appendix A. Mathematical model}

\section{A.1 Mass and salt balances}

\section{Membrane distillation unit}

Mass and salt balances around each membrane distillation are given by the following equations

$$
f_{n}^{\text {memb }}+f_{n}^{r e c}=f_{n}^{r e c}+f_{n}^{\text {perm }}+f_{n}^{r e j} \quad \forall n \in N
$$

$$
f_{n}^{m e m b} \cdot x_{n}^{m e m b}=f_{n}^{r e j} \cdot x_{n}^{r e j} \quad \forall n \in N
$$

\section{(A.1.2)}

where, $f_{n}^{\text {memb }}, f_{n}^{\text {rec }}, f_{n}^{\text {perm }}$ and $f_{n}^{\text {rej }}$ represent the inlet mass flowrate, the recirculated flowrate, the permeate flowrate and the reject flowrate in the membrane module, respectively. $x_{n}^{m e m b}$ and $x_{n}^{r e j}$ are the inlet and reject concentration in the membrane.

\section{Recycle splitter}

The possibility of various recycle connections is defined by the following equation:

$$
f_{n}^{\text {rej }}=f_{n}^{\text {recycle }}+\sum_{\substack{n \\ n>N \\ n>n^{\prime}}} f_{n, n^{\prime}}^{\text {recycle }}+f_{n}^{\text {conc }} \quad \forall n \in N
$$

\section{(A.1.3)}

Where $f_{n}^{\text {recycle }}, f_{n, n^{\prime}}^{\text {recycle }}$ and $f_{n}^{\text {conc }}$ represent the direct recycle, the inter-stage recycles and the concentrate stream, respectively. The concentration, temperature and, consequently, the specific enthalpy of these streams are the same as for the reject stream.

\section{Inlet mixer balances}


A. Carrero-Parreño et al.

The membrane inlet conditions are defined by the following mass, salt an energy balances around the inlet mixer placed before each membrane module.

$$
\begin{aligned}
& f_{n}^{\text {stage }}+f_{n}^{\text {recycle }}+\sum_{\substack{n^{\prime} \in N \\
n>n^{\prime}}} f_{n, n^{\prime}}^{\text {recycle }}=f_{n}^{\text {memb }} \quad \forall n \in N \\
& f_{n}^{\text {stage }} x_{n}^{\text {feed }}+f_{n}^{\text {recycle }} \cdot x_{n}^{\text {rej }}+\sum_{\substack{n^{\prime} \in N \\
n>n^{\prime}}} f_{n, n^{\prime}}^{\text {recycle }} \cdot x_{n^{\prime}}^{r e j} \quad=f_{n}^{\text {memb }} \cdot x_{n}^{\text {memb }} \quad \forall n \in N
\end{aligned}
$$

$$
\begin{aligned}
& h_{n}^{s}\left(t_{n}^{\text {feed }}, x_{n}^{\text {feed }}\right) \cdot f_{n}^{\text {stage }}+h_{n}^{s}\left(t_{n}^{\text {rej }}, x_{n}^{\text {rej }}\right) \cdot f_{n}^{\text {recycle }}+ \\
& +\sum_{\substack{n^{\prime} \in N \\
n>n^{\prime}}} h_{n^{\prime}}^{s}\left(t_{n^{\prime}}^{\text {rej }}, x_{n^{\prime}}^{r e j}\right) \cdot f_{n, n^{\prime}}^{\text {recycle }}=h_{n}^{s}\left(t_{n}^{h x, i n}, x_{n}^{\text {memb }}\right) \cdot f_{n}^{\text {memb }} \quad \forall n \in N
\end{aligned}
$$

\section{A.2 Permeate flux calculation}

The permeate flux throughout the membrane is calculated as proposed by Elsayed et al.

$$
j_{n}=B \cdot\left(p_{n}^{m 1} \cdot \gamma_{n}\left(1-\omega_{n}\right)-p_{n}^{m 2}\right) \quad \forall n \in N
$$

\section{(A.2.1)}

in which, B is the membrane permeability, $\omega_{n}$ is the salt molar fraction in the feed side, $\gamma_{n}$ represents the activity coefficient of the water in the feed side, and $p_{n}^{m 1}$ and $p_{n}^{m 2}$ are the vapor pressures at both sides of the membrane surface (see Fig.3). The salt molar fraction of the feed water is given by Eq. (A.2.2).

$$
\omega_{n} \cdot\left(x_{n}^{\text {memb }} / 58.4+\left(1-x_{n}^{m e m b} / 18\right)=x_{n}^{\text {memb }} / 58.4 \quad \forall n \in N\right.
$$

\section{(A.2.2)}

The activity coefficient is estimated as a function of the salt molar concentration by the following equation as proposed by Lawson and Lloyd (1996), 
$\gamma_{n}=1-0.5 \cdot \omega_{n}-\left(10 \cdot \omega_{n}\right)^{2} \quad \forall n \in N$

\section{(A.2.3)}

Vapor pressure is estimated with the correlation described in Eq. (A.2.4), which has been obtained using Antoine's equation for the range of the working temperatures (20 $\left.{ }^{\circ} \mathrm{C}-90{ }^{\circ} \mathrm{C}\right)$.

$$
p_{n}=16.56 \cdot\left(t_{n}\right)^{2}-935.90 \cdot t_{n}+16960 \quad \forall n \in N
$$

\section{(A.2.4)}

\section{A.3 Heat Exchanger and cooler design equations}

The following equations and variables are used to model mathematically the heat exchanger and cooler. They can be described in four blocks of equations. The first one defines the energy balance across the equipment, the second one calculates the equipment area, in the third one Chen's approximation is applied to calculate the temperature difference and the last one ensures the workability of the equipment.

\section{Heat Exchanger}

Energy balance

$$
\begin{aligned}
& \left(f_{n}^{\text {rec }}+f_{n}^{\text {perm }}\right) \cdot\left(h_{n}^{p}\left(t_{n}^{\text {perm }}\right)-h_{n}^{p}\left(t_{n}^{\text {perm }}\right)\right)= \\
& =f_{n}^{\text {memb }} \cdot\left(h_{n}^{s}\left(t_{n}^{h x, \text { out }}, x_{n}^{\text {memb }}\right)-h_{n}^{s}\left(t_{n}^{\text {hx,in }}, x_{n}^{\text {memb }}\right)\right) \quad \forall n \in N
\end{aligned}
$$

\section{(A.3.1)}

Heat exchanger area calculation

$a_{n}^{h x} \cdot U^{h x} \cdot \operatorname{lmtd}_{n}^{h x}=q_{n}^{h x} \quad \forall n \in N$

\section{2)}

Chen's approximation for the calculation of logarithmic mean temperature difference 
A. Carrero-Parreño et al.

$\operatorname{lmtd}_{n}^{h x}=\left(0.5 \cdot\left(\theta_{n}^{3} \cdot \theta_{n}^{4}\right)\left(\theta_{n}^{3}+\theta_{n}^{4}\right)\right)^{1 / 3} \quad \forall n \in N$

3.3)

$\theta_{n}^{3}=t^{\text {perm }}-t_{n}^{h x, \text { out }} \quad \forall n \in N$

(A.

3.4)

$\theta_{n}^{4}=t_{n}^{\text {perm' }}-t_{n}^{h x, \text { in }} \quad \forall n \in N$

(A.

Design temperature constraints

$\Delta T^{\text {min }} \leq t^{\text {perm }}-t_{n}^{\text {hx,out }} \quad \forall n \in N$

$\Delta T^{\text {min }} \leq t_{n}^{\text {perm' }}-t_{n}^{\text {hx,in }} \quad \forall n \in N$

\section{Cooler}

Energy balance

$q_{n}^{\text {cooler }}=f_{n}^{r e c} \cdot\left(h_{n}^{p}\left(t_{n}^{\text {perm }}\right)-h_{n}^{p}\left(t_{n}^{r e c}\right)\right) \quad \forall n \in N$

(A.

3.8)

Area calculation

$a_{n}^{\text {cooler }} \cdot U^{\text {cooler }} \cdot \operatorname{lmtd}{ }_{n}^{\text {cooler }}=q_{n}^{\text {cooler }} \quad \forall n \in N$

3.9)

Chen's approximation for the calculation of logarithmic mean temperature difference

$\operatorname{lmtd}_{n}^{\text {cooler }}=\left(0.5 \cdot\left(\theta_{n}^{5} \cdot \theta_{n}^{6}\right)\left(\theta_{n}^{5}+\theta_{n}^{6}\right)\right)^{1 / 3} \quad \forall n \in N$ 
A. Carrero-Parreño et al.

$\theta_{n}^{5}=t_{n}^{\text {perm' }}-T^{\text {refrig,out }} \quad \forall n \in N$

(A.

3.11)

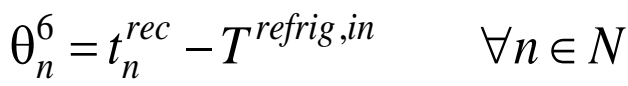

(A.

3.12)

Design temperature constraints

$\Delta T^{\text {min }} \leq t_{n}^{\text {perm' }}-T^{\text {refrig,out }} \quad \forall n \in N$

(A.

3.12)

$\Delta T^{\text {min }} \leq t_{n}^{r e c}-T^{\text {refrig,in }} \quad \forall n \in N$

(A.

3.13) 
A. Carrero-Parreño et al.

Appendix B. Aspen Hysys ${ }^{\circledR}$ flow diagram and comparison between mathematical model and simulated results.

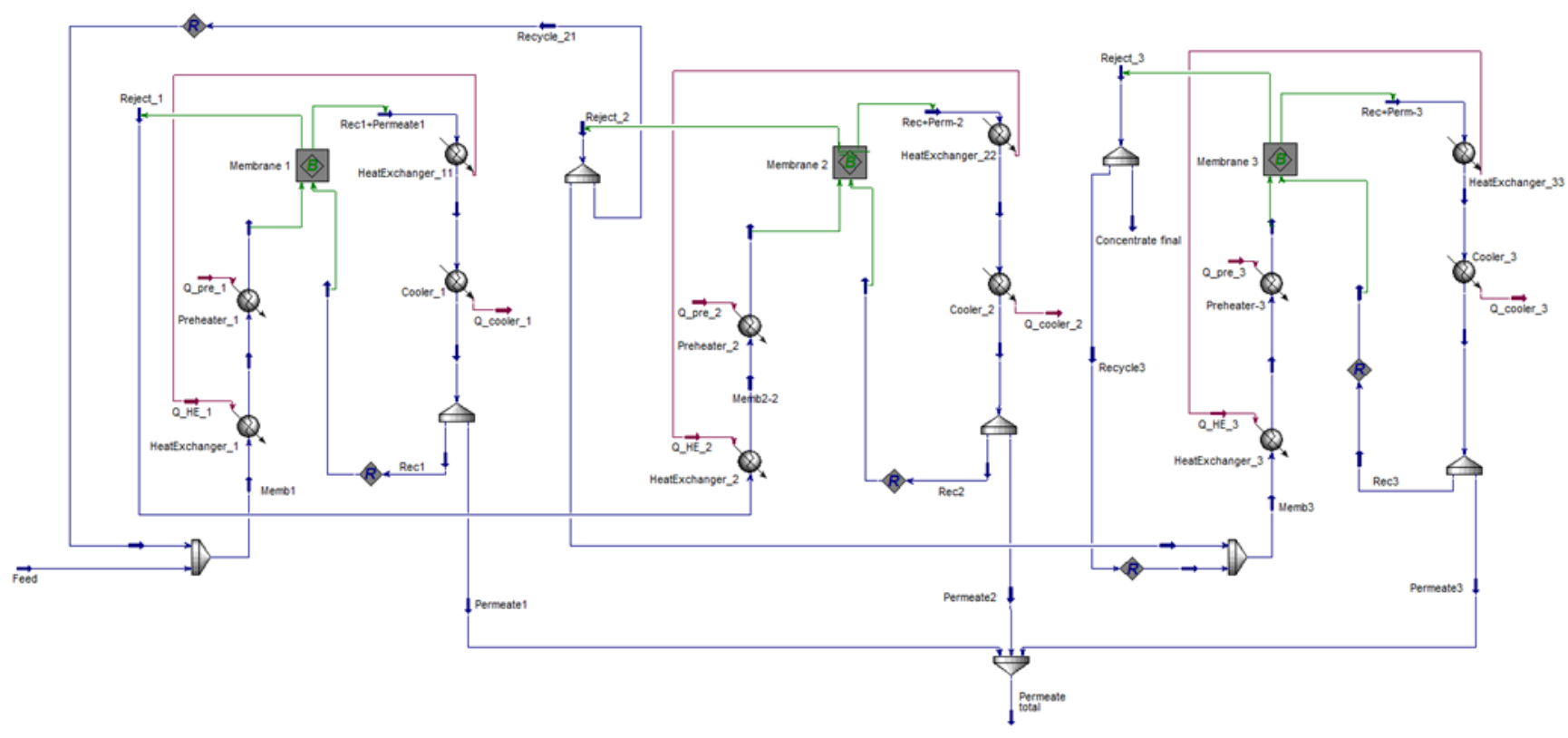

Fig. B.1 Membrane distillation system process flow diagram in Aspen HYSYS ${ }^{\circledR}$ of the optimal solution for the base case. 
A. Carrero-Parreño et al.

Table B.1 Process variables for the optimal solution of the MDS model and values obtained from the simulation.

\begin{tabular}{|c|c|c|c|c|}
\hline Process Variables & Stage & Model & Hysys & Relative error (\%) \\
\hline & 1 & 1185 & 1191 & -0.50 \\
\hline \multirow[t]{3}{*}{ Heat flow preheater (kW) } & 2 & 1176 & 1183 & -0.59 \\
\hline & 3 & 976 & 986 & -1.01 \\
\hline & 1 & 3130 & 3113 & 0.54 \\
\hline \multirow[t]{3}{*}{ Heat flow heat exchanger (kW) } & 2 & 3068 & 3053 & 0.49 \\
\hline & 3 & 2192 & 2186 & 0.27 \\
\hline & 1 & 1175 & 1181 & -0.51 \\
\hline \multirow[t]{3}{*}{ Heat flow cooler $(\mathrm{kW})$} & 2 & 1166 & 1173 & -0.60 \\
\hline & 3 & 968 & 977,90 & -1.01 \\
\hline & 1 & 80.78 & 80.69 & 0.11 \\
\hline \multirow[t]{2}{*}{ Permeate temperature $\left({ }^{\circ} \mathrm{C}\right)$} & 2 & 80.60 & 80.50 & 0.12 \\
\hline & 3 & 78.44 & 78.52 & -0.10 \\
\hline Final concentrate $\left(\mathrm{kg} \cdot \mathrm{s}^{-1}\right)$ & - & 1.33 & 1.33 & 0.00 \\
\hline Final permeate $\left(\mathrm{kg} \cdot \mathrm{s}^{-1}\right)$ & - & 0.66 & 0.66 & 0.00 \\
\hline
\end{tabular}

